\title{
A Comparison of NGA-West2 Ground-Motion Models to Recent Chinese Data
}

\author{
Chen Huang, Carmine Galasso* \\ Department of Civil, Environmental and Geomatic Engineering, University College London, London, WC1E 6BT, \\ England, UK
}

\begin{abstract}
Sichuan Province is one of the most seismically active areas in China. Several major earthquakes have struck this region in recent years, including the $2008 M_{w} 7.9$ Wenchuan earthquake, the $2013 M_{w} 6.6$ Lushan earthquake, and the $2017 M_{w} 6.5$ Jiuzhaigou earthquake, causing vast socio-economic loss. These events have considerably expanded the ground-motion database for China, with high-quality records that can be used to improve ground-motion models (GMMs) for China and worldwide, and for advancing seismic hazard assessment. This study investigates the compatibility of advanced GMMs established by the NGA-West2 (Enhancement of Next Generation Attenuation Relationships for Western US) project for application to shallow crustal earthquakes in tectonically active regions and a local GMM for China with the recent Chinese strong-motion data. Specifically, this study quantitatively investigates the compatibility of these models with respect to magnitude scaling, source-to-site distance scaling, and site-effect scaling implied by the considered Chinese data. The results show that the Chinese data is characterized by slower attenuation with respect to the NGA-West2 GMMs. Regression coefficients are re-estimated for the considered GMMs based on the Sichuan data. These updated international and local GMMs can be applied for seismic hazard analysis in Sichuan. The comparisons between the extended ground-motion database for the Sichuan Province and the updated NGA-West2 GMMs represent an important first step toward the future development of new, improved GMMs for Sichuan and, ultimately, for China.
\end{abstract}

Keywords: Ground-motion models, China, NGA-West2, Intensity measures

\section{Introduction}

Sichuan Province is one of the most seismically active areas in China, with a long history of devastating earthquakes caused by the complex geographic and tectonic setting in the region. Specifically, Sichuan is located in southwest China, occupying most of the Sichuan Basin and the easternmost part of the Tibetan Plateau, between the Jinsha River on the west, the Daba Mountains in the north, and the Yungui Plateau to the south. Due to the collision between the Indian Plate and the Eurasian Plate, the Longmenshan fault was developed throughout the Cenozoic era [1] and caused both the $2008 M_{w} 7.9$ Wenchuan earthquake [2] and the $2013 M_{w}$ 6.6 Lushan earthquake [3]. Recently, on 8 August 2017, the

\footnotetext{
* Corresponding author

Email addresses: chen.huang.14@ucl.ac.uk (Chen Huang), c.galasso@ucl.ac.uk (Carmine Galasso)
} 
$M_{w}$ 6.5 Jiuzhaigou earthquake struck Sichuan, which was caused by the Kunlun fault in the region [4].

These moderate-to-large earthquake events have caused huge socio-economic loss. It is reported that the Wenchuan earthquake resulted in 88,000 fatalities or missing people, nearly 400,000 injuries, and five million people homeless [5]. Several buildings and infrastructure were damaged and severe cascading hazards (e.g., landslides and debris flows) were triggered by the Wenchuan earthquake [6]. The direct economic loss of the Wenchuan earthquake was estimated at US\$ 123 billion [7]. The Lushan earthquake, although characterized by a magnitude smaller than the Wenchuan earthquake, resulted in 193 fatalities, 25 missing people and over 12,000 injuries, causing extensive large-scale landslides and structural damage [3. The economic loss of the Lushan earthquake was approximately US $\$ 48.4$ million [8]. The Jiuzhaigou earthquake, with a similar magnitude to the Lushan earthquake, caused 25 fatalities and 525 injuries due to the seismically induced geotechnical hazards [9]. The economic loss of the Jiuzhaigou earthquake was over RMB 8 billion (i.e., approximately US\$ 1.2 million) [10. The earthquake-triggered landslides severely affected the Jiuzhaigou Valley, a World Natural Heritage Site selected by the United Nations Educational, Scientific, and Cultural Organization (UNESCO) [1]. However, the Jiuzhaigou earthquake did not cause substantial structural damage [9].

These destructive events have been well-recorded by the China National Strong Motion Observation Network System (NSMONS) managed by the China Earthquake Administration (CEA), which has been in operation since March 2008 [12. The quantity and quality of these records have significantly improved the strong-motion database for China, promoting research in earthquake engineering and engineering seismology, in particular, for the characterizations of ground-motion data of moderate-to-large earthquakes and the development of new ground-motion models (GMMs) for probabilistic seismic hazard analysis (PSHA) in China.

This study focuses on the three recent events in Sichuan introduced above and investigates the compatibility of the NGA-West2 (Enhancement of Next Generation Attenuation Relationships for Western US) GMMs [13 17, hereafter referred to as ASK14, BSSA14, CB14, CY14 and I14] and a local Chinaspecific GMM [18, hereafter Huo89] to this Chinese strong-motion data. The model compatibility is investigated in terms of magnitude scaling, source-to-site distance scaling, and site-effect scaling. Moreover, the coefficients corresponding to the constant term, the geometric spreading term and the linear site response term in the considered GMMs are re-estimated based on the Sichuan data. The comparisons between the NGA-West2 GMMs and the extended ground-motion database for the Sichuan Province represent an important first step towards the future development of new, improved GMMs for Sichuan and, ultimately, for China.

This paper is organized as follows. We first review several studies comparing various GMMs to Chinese ground-motion data, followed by an introduction of the dataset used in this study, highlighting some issues in the site characterization. Then, we statistically evaluate the different horizontal groundshaking definitions, followed by a preliminary evaluation of the polarization in the dataset. A series of qualitative and quantitative analyses of the considered GMMs with respect to the Sichuan data in terms of magnitude scaling, source-to-site distance scaling, and site-effect scaling are carried out. Finally, some coefficients in the considered GMMs are re-estimated to address the specific features observed in the 
Sichuan data.

\section{Literature Review}

Engineering analysis of local and worldwide recent strong-motion data with respect to state-of-theart GMMs is beneficial for several reasons. Firstly, this allows one to evaluate whether a previously developed GMM is consistent with the newly available data, in order to improve the model performance. Moreover, one can assess the features of the new data and possibly implement modifications in GMMs if the new data is included. In addition, analyzing the compatibility between GMMs and ground-motion data can help to increase the confidence in model applications (e.g., seismic risk assessment exercises and the definition of target spectra for performance-based earthquake engineering or PBEE).

A set of ad-hoc GMMs for worldwide shallow crustal regions developed by the Pacific Earthquake Engineering Research Center (PEER) are usually used as state-of-the-art and state-of-practice benchmark GMMs for such analysis. Those models include the NGA-West (Next Generation of Ground-Motion Attenuation Models for the Western US) GMMs [19 23, hereafter referred to as AS08, BA08, CB08, CY08 and I08] developed based on a global strong-motion database consisting of 3,551 multi-component records from 173 shallow crustal earthquakes between 1935 and 2003, ranging in magnitude from 4.2 to 7.9 [24], and the updated NGA-West2 GMMs, developed based on a larger repository consisting of 21,336 (over 98\%) three-component records from 599 events till 2011, ranging in magnitude from 3.0 to 7.9 [25]. Because of the large quantity and high quality of the NGA-West2 database, certain effects (e.g., the nonlinear site response) are well resolved in some of the NGA-West2 GMMs that could not be evaluated using only Chinese data. A general review of GMMs published prior to 2016 is given by Douglas and Edwards [26].

For this type of comparisons, the predictive variables required by the considered GMMs need to be estimated, including but not limited to, magnitude in terms of moment magnitude $\left(M_{w}\right)$ and surface magnitude $\left(M_{s}\right)$; source-to-site distance in $\mathrm{km}$ in terms of rupture distance $\left(R_{\text {rup }}\right)$, the closest distance to the surface projection of the fault rupture or Joyner-Boore distance $\left(R_{J B}\right)$, epicentral distance $\left(R_{e p i}\right)$, and the horizontal distance from a site to the top edge of the rupture measured perpendicular to the strike of the fault $\left(R_{X}\right)$; style-of-faulting; the average shear-wave velocity in the upper $30 \mathrm{~m}$ soil $\left(V_{S 30}\right) \mathrm{in} \mathrm{m} / \mathrm{s}$; the depth to the top of rupture $\left(Z_{t o r}\right)$ in $\mathrm{km}$; the depth to $V_{S 30}=1.0 \mathrm{~km} / \mathrm{s}\left(Z_{1.0}\right)$ in $\mathrm{km}$; the depth to $V_{S 30}=$ $2.5 \mathrm{~km} / \mathrm{s}\left(Z_{2.5}\right)$ in $\mathrm{km}$; the fault dip in degrees; the rupture width in $\mathrm{km}$; region-specific parameter for anelastic attenuation. Hence, these models are considerably more complicated than previous ones, often requiring several additional input parameters that are unknown. For instance, Kaklamanos et al. [27] introduced a framework for estimating the unknown source, path, and site parameters when implementing the NGA models in the engineering practice.

Several studies [e.g., 9, 12, 28 36] have investigated the compatibility of worldwide and Chinese GMMs to Chinese strong-motion data, in particular, to the aforementioned three major events in Sichuan. The main findings of these studies are summarized in Appendix and some common findings are as follows:

- In the case of the Wenchuan earthquake, the observed peak ground acceleration (PGA) and short- 
period spectral ordinates are generally higher than the predictions of the reference GMMs over the considered distance range while long-period spectral ordinates are lower than those predicted by the reference GMMs over the distance range;

- In the case of the Lushan earthquake and the Jiuzhaigou earthquake, the observed PGA and shortperiod spectral ordinates are generally consistent with the predictions of the reference GMMs over the considered distance range while long-period spectral ordinates are lower than those predicted by the reference GMMs over the distance range;

- Directivity effect (i.e., the focusing of seismic wave energy along the fault in the direction of rupture) and hanging-wall effect (i.e., the increase in ground motion at short distances for sites on the hanging wall side of a rupture when compared to sites on the footwall side at the same closest distance) are detected in the Wenchuan earthquake and the Lushan earthquake;

- China ground motions attenuate more slowly with respect to source-to-site distance than the reference GMMs, possibly due to the higher values of the shear-wave quality factor $Q$ for China than those implied by the reference GMM.

Although most of the considered studies focus on a single earthquake, Ji et al. [35] and Dangkua et al. [36] investigate the model compatibility using pooled Chinese data from multiple earthquakes. Their results show that the Chinese GMMs of Huo89 and Yu et al. 37] and NGA-West2 GMMs are generally consistent with the observations of PGA and short-period spectral ordinates over the considered distance range while these GMMs overpredict the long-period spectral ordinates over the considered distance range. It is worth pointing out that, although there are more recent China-specific GMMs [e.g., 37] compared to Huo89, they are only applicable to rock sites while Huo89 is applicable to both rock and soil sites. Because site effect has an important impact on ground motions, this study has chosen the Huo89 model, a widely used GMM for seismic-hazard assessment in China [35, for comparison. Moreover, Dangkua et al. [36] found that Chinese ground motions attenuate more slowly with respect to sourceto-site distance than the NGA-West2 GMMs. Furthermore, Dangkua et al. 36] observed some residual biases in the NGA-West2 and Chinese GMMs corresponding to the source-to-site distance scaling and magnitude scaling with respect to Chinese data, which implies that these GMMs may need adjustments to account for the specific features observed in the pooled Chinese data. However, it is noteworthy that the multi-event database used in these studies implicitly assumed homogeneous geological conditionals across a fairly large geographic area, which requires further investigation.

It is also shown in Appendix that a variety of data and methods have been used in the considered studies. For instance, most of the studies deal with data from NSMONS while Dangkua et al. [36] used a mixed dataset of NSMONS and NGA-West2. The processing methods applied to the ground-motion data in Wang et al. 29] and Bai [34] follow the NGA-West2 procedure, while Ren et al. 9], Wen and Ren [32] and Ji et al. [35] select different processing procedures; in both cases, the processing approaches may be different from the one used by NSMONS. Moreover, various definitions of the horizontal groundshaking intensity measures (IMs) are used in these studies. For instance, the geometric mean definition 
is used by most Chinese GMMs; the GMRotI50 definition (i.e., the median orientation-independent geometric mean, using period-independent rotation angle) proposed by Boore [38] is used in Bai [34; and the RotD50 definition (i.e., the median orientation-independent non-geometric-mean measure, using period-dependent rotation angle) proposed by Boore [39] is used in Ren et al. 9. Furthermore, the site classification used in each study consists of the two-category site classification provided by NSMONS (i.e., rock or soil), the five-category site classification (shown in Table 1) specified in the China Code for Seismic Design of Buildings (GB50011-2010) [40] based on $V_{S 20}$ (i.e., the average shear-wave velocity in the upper $20 \mathrm{~m}$ soil, in $\mathrm{m} / \mathrm{s}$ ) and soil depth, and the six-category site classification (A to F) defined in the National Earthquake Hazards Reduction Program (NEHRP) [41 based on $V_{S 30}$. Since $V_{S 20}$ is the considered site-classification parameter in GB50011-2010, the $V_{S 30}$ value required by the international GMMs is estimated or assigned based on various standards or engineering judgements, resulting in different $V_{S 30}$ values for same sites used in different studies. In addition, several studies fit trend lines to residuals (e.g., total residuals, inter-event residuals or intra-event residuals) in order to analyze whether there is potential bias in GMMs. However, the method used to compute the inter-event residuals varies, such that, Dangkua et al. 36] follow the equations in Abrahamson and Youngs 42] while Wang et al. 29] use the average of total residual as the inter-event residuals for the Wenchuan earthquake.

[Table 1 about here.]

The above discussions suggest a general lack of consistency in comparing the Chinese data and the state-of-the-art GMMs across different studies. This may lead to model/data misinterpretation, biased results, and unsuitable GMMs used in performing PSHA for Sichuan Province. Therefore, this study presents a systematic way to compare GMMs to the ground-motion data of three most relevant recent Chinese earthquakes in Sichuan. A similar method has been used by Scasserra et al. [43] for Italian data. In addition, this study statistically investigates the different definitions of horizontal ground-shaking IMs. Moreover, this study assesses the improvement on model performance before and after accounting for the features observed in the Sichuan data, as further discussed in the following sections.

\section{Dataset}

The strong-motion data for the considered Sichuan earthquakes are collected from NSMONS and are processed according to standard practice by researchers at CEA (e.g., applying an acausal Butterworth filter with corner frequencies of $0.1 \mathrm{~Hz}$ and $30 \mathrm{~Hz}$ and baseline correction - personal communication). It is worth noting that the CEA processing procedure may be different from that used by the NGAWest2 regarding the selection of record and component-specific corner frequencies. In particular, the two-component horizontal records with $R_{J B} \leq 250 \mathrm{~km}$ are selected in this study. The $250 \mathrm{~km}$ cut-off distance is within the applicable distance range of most NGA-West2 GMMs while the distance range of I14 GMM is extrapolated to $250 \mathrm{~km}$. The geographic distribution of the recording stations and the $M_{w}-R_{J B}$ distribution with the NSMONS site classification are presented in Figure 1 The metadata for each considered event is listed in Table 2 
[Figure [1]about here.]

[Table 2 about here.]

The considered GMMs in this paper are the five NGA-West2 GMMs and the Huo89 GMM. The magnitude metric $M_{w}$ is used by the NGA-West2 GMMs while $M_{s}$ is used by Huo89. Given the finitefault models in Table2, several predictor variables required by these GMMs can be calculated accordingly. The region-specific parameters, e.g., region predictor in ASK14 and BSSA14, the coefficient of regional differences $\Delta c_{20}$ in CB14, and the multiplicative adjustment factor $\gamma$ in CY14 for anelastic attenuation are chosen for China accordingly.

\subsection{Site classifications and $V_{S 30}$ of stations}

The knowledge of $V_{S 30}$ is generally required by advanced GMMs (e.g., NGA-West2 GMMs). The $V_{S 30}$ accounts for the local site conditions and its accuracy has a huge impact on the GMM fitting and its applications. In fact, the local site conditions can modify the amplitude, frequency, and duration of the seismic shaking. As discussed in Section 2 and Appendix, various measurements/estimations of $V_{S 30}$ are used in the literature. Though similar results are observed in these studies, different $V_{S 30}$ values of the recording sites may shift the median predictions used as a reference in each comparison. Thus, this type of visual comparisons can only provide a general guidance on the overall goodness-of-fit while detailed analysis of residuals, as performed in this study, could provide more insights into the model performance.

To further elaborate on this issue, the $V_{S 30}$ estimated from two different methods is examined. Yu [44] obtained the $V_{S 20}$ soil profiles from in-situ borehole tests for 147 stations in Sichuan Province and Gansu Province. Assuming the soil medium is unchanged from the bottom of the borehole till $30 \mathrm{~m}$ depth, Yu extrapolated the $V_{S 20}$ values to estimate $V_{S 30}$ for all stations; 80 stations out of the 147 above are used in this study ( $V_{S 30}$ values at these 80 stations are denoted by $\left.V_{S 30, Y u}\right)$. Alternatively, the USGS $V_{S 30}$ Models and Data provides $V_{S 30}$ values ( $V_{S 30, \text { USGS }}$ hereafter) derived through approximated relationships

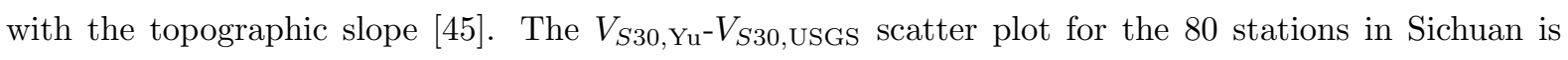

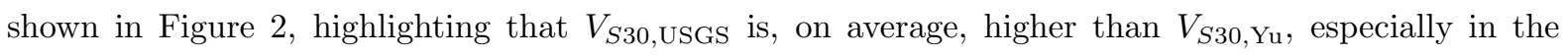
range $V_{S 30, \text { USGS }} \geq 500 \mathrm{~m} / \mathrm{s}$ (shaded area). According to GB50011-2010, a soil layer with a shear-wave velocity $\geq 500 \mathrm{~m} / \mathrm{s}$ is regarded as bedrock. Yu stated that when the drilling depth (from ground surface to bedrock) is significantly $\leq 20 \mathrm{~m}$, there is greater uncertainty in the extrapolated value.

[Figure 2 about here.]

For the purpose of this study, the $V_{S 30}$, Yu value at each site/station is used as the preferred value in the analysis and, if this data is not available, the $V_{S 30 \text {,USGS }}$ is used instead. It is worth noting that different $V_{S 30}$ estimation procedures were used in NGA-West2 for Chinese stations. Specifically, in the case of stations for which the $V_{S}$ profiles are not available, values have been inferred $V_{S 30}$ from multiple proxies, such as the ground slope (as done here), a geotechnical proxy, and a terrain proxy [25]. However, the various estimation procedures result in a generally consistent site-class classification. However, as shown above, available information at seismic stations are frequently inadequate for a proper characterization of local site conditions and this can have a significant impact on the seismic hazard estimates at both 
large and local scale. Thus, there is an urgent need to invest in site characterization of the recording stations in China in order to improve the current knowledge on strong-motion seismology.

\section{Horizontal ground-shaking definitions}

Different horizontal ground-shaking definitions are used in various GMMs, as mentioned above. Several studies [e.g., 39, 46, 47] showed that the differences among these definitions from global databases are minimal (negligible at low periods and generally less than 5-8\%). Moreover, Shahi and Baker [48] suggest the ratios of maximum-to-median IM across orientations (i.e., RotD100/RotD50, where RotD100 is the maximum orientation-independent non-geometric-mean measure, using period-dependent rotation angle proposed by Boore [39]) can be used as a proxy for the polarization of ground motions, which is important for analyzing the structural responses of 3-Dimensional (3-D) structural models in all orientations. Thus, this section first analyzes whether the differences between RotD50 and geometric mean definitions are statistically significant in the Sichuan data and then investigates the polarization in the considered dataset.

The median ratio between RotD50 and the geometric mean definition in terms of spectral acceleration $\left(S_{a}\right), S_{a, \mathrm{RotD} 50} / S_{a, \mathrm{GM}}$, computed from all the considered earthquakes are presented in Figure 3 together with its standard deviation. It is worth noting that the results are computed as the exponential of the mean and standard deviation of the natural logarithm of $S_{a, \mathrm{RotD} 50} / S_{a, \mathrm{GM}}$ as a function period $T$. These estimates are useful for the conversion from a GMM for one definition to another, accounting for the propagation of uncertainty [46]. The median $S_{a, \mathrm{RotD} 50} / S_{a, \mathrm{GM}}$ in Figure 3 (a) is slightly larger than unity ( $\leq 1.05$ ), which suggests the two horizontal ground-shaking definitions give similar $S_{a}$ amplitude. Moreover, the median $S_{a, \text { RotD } 50} / S_{a, \mathrm{GM}}$ slightly increases as the structural period $T$ increases, reaching about 1.05 at $T=5 \mathrm{~s}$. Beyer [46] argued that these increments may be due to "the stronger polarization of ground-motion waves". The standard deviation of $S_{a, \text { RotD } 50} / S_{a, \mathrm{GM}}$ in Figure 3 (b) increases with $T$ from about 1.06 to 1.1 at $T=5 \mathrm{~s}$, which is consistent with literature [e.g., 39]. However, these small values may not significantly increase the total standard deviations when converting GMM for RotD50 from geometric mean.

[Figure 3 about here.]

Besides the amplitude of different horizontal ground-shaking definitions, the distributions of different definitions are also critical for PSHA applications and the GMM conversion between different definitions.

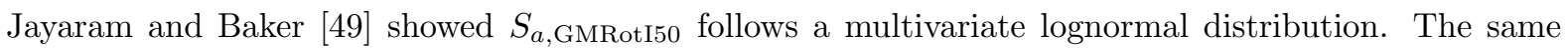
assumption is applied explicitly or implicitly when developing GMMs for other definitions. This section visually evaluates the IM distributions of RotD50 and geometric mean definitions by a quantile-quantile (Q-Q) plot, which is a graphical method used to determine whether the two samples come from the same distribution or not. If two samples come from a population with the same distribution, the data points should fall approximately along a 45-degree reference line. The Q-Q plot of $\ln \left(\operatorname{IM}_{\mathrm{RotD} 50}\right)$ versus $\ln \left(\mathrm{IM}_{\mathrm{GM}}\right)$ in Figure 4 shows an approximately 45-degree straight line, suggesting that the difference in IM distributions of two definitions are not statistically significant. Thus, the differences between RotD50 
and geometric mean definitions in Sichuan data regarding amplitude (i.e, point estimate) and distribution are insignificant. Therefore, to be consistent with NGA-West2 GMMs, RotD50 definition is used in the following sections for model comparisons and adjustments.

[Figure 4 about here.]

Regarding the polarization in ground motions, Shahi and Baker [48] suggest that, if RotD100/RotD50 $\sqrt{2}$, the structural response is polarized in one orientation while if $\operatorname{RotD} 100 / \operatorname{RotD} 50 \approx 1$, the structural response is similar in all orientations. As an example, Figure 5 presents the displacement trace and $S_{a}$ over all orientations for representative stations/records. As shown in Figure 5 (a), the response at station $51 \mathrm{GYZ}$ in the Wenchuan earthquake shows little polarization with $S_{a, \text { RotD100 }} / S_{a, \text { RotD50 }} \approx 1.08$ while $51 \mathrm{MZQ}$ station in Figure 5 (b) shows a relatively strong polarization with $S_{a, \operatorname{RotD} 100} / S_{a, \operatorname{RotD} 50} \approx 1.33$. As shown in Figure 5 (c) and (d), the structural responses at station 51PJD in the Lushan earthquake and at station $62 \mathrm{WYX}$ in the Jiuzhaigou earthquake show some polarization with $S_{a, \operatorname{RotD} 100} / S_{a, \operatorname{RotD} 50} \approx$ 1.22. Therefore, there is a certain degree of polarization in the Sichuan data and these data should be used with caution for the analysis of 3-D structural models. Moreover, the $S_{a, \text { RotD100 }} / S_{a, \text { RotD50 }}$ ratio is compared with the empirical model of Shahi and Baker [48] at representative periods, as shown in Figure 6, which shows that the ratios observed in the Sichuan data are consistent with the international model.

[Figure 5 about here.]

[Figure 6 about here.]

\section{Comparisons of the median predictions from GMMs}

In this section, the Sichuan data are first visually compared with the median predictions of PGA, and $S_{a}$ at two representative periods (i.e., $0.1 \mathrm{~s}$ and $1.0 \mathrm{~s}$ ) from the considered GMMs, as shown in Figure 7 For illustrative purpose, $V_{S 30}$ is set to $450 \mathrm{~m} / \mathrm{s}$ (i.e., stiff soil and Class C in NEHRP) because it is close to the median $V_{S 30}$ value $375 \mathrm{~m} / \mathrm{s}$ of the Sichuan stations and I14 is only applicable for $V_{S 30} \geq 450 \mathrm{~m} / \mathrm{s}$. The distance metric for ASK14, CB14, CY14, and I14 is $R_{\text {rup }}, R_{J B}$ for BSSA14 and $R_{e p i}$ for Huo89. No hanging wall effect is assumed and the region-specific parameters are chosen for China. The basin depth terms, $Z_{1.0}$ and $Z_{2.5}$, are empirically estimated from $V_{S 30}$ based on several NGA-West2 studies, as follows,

- Chiou and Youngs [16] model for $Z_{1.0}$ used in ASK14 and CY14:

$$
Z_{1.0}=\frac{1}{1000} \exp \left[-\frac{7.67}{4} \ln \left(\frac{V_{S 30}^{4}+610^{4}}{1360^{4}+610^{4}}\right)\right]
$$

- Boore et al. [14] model for $Z_{1.0}$ used in BSSA14:

$$
Z_{1.0}=\frac{1}{1000} \exp \left[-\frac{7.15}{4} \ln \left(\frac{V_{S 30}^{4}+570.94^{4}}{1360^{4}+570.94^{4}}\right)\right]
$$

- Campbell and Bozorgnia [15] model for $Z_{2.5}$ used in CB14:

$$
Z_{2.5}=\exp \left(7.089-1.144 \ln V_{S 30}\right)
$$


It is well-recognized that these empirical estimations for the basin depths dependent on $V_{S 30}$ are developed based on the global dataset (mostly California data and excluding Japan data) and may not apply to Sichuan, China. Scasserra et al. 43] suggest that "if the average basin effect implied by the NGA GMMs is significantly in error, it would be expected to produce bias at long periods", which is discussed in the subsequent section. More in general, these visual comparisons provide a general guidance of the goodness-of-fit while detailed analysis of residuals will be carried out in the following sections.

As shown in Figure 7(a), (d), and (g), regarding the Wenchuan earthquake, there is an overall good agreement between the predictions of the NGA-West2 GMMs and the observations in terms of PGA and short-period spectral ordinates over the considered distance range. However, some GMMs overestimate the long-period spectral ordinates, particularly, in the far field. Though the data in the near field is sparse, the considered GMMs are generally consistent with the data. These results are expected since this event is included in the NGA-West2 database for the calibration of the NGA-West2 GMMs. The Huo89 gives a similar median prediction as that of the NGA-West2 GMMs for short-period spectral ordinates but Huo89 overestimates the long-period spectral ordinates. Regarding the Lushan earthquake in Figure 7 (b), (e), and (h), the NGA-West2 GMMs are consistent with PGA and short-period spectral ordinates data in the near field but overestimate them in the far field, and the NGA-West2 GMMs slightly overestimate the long-period spectral ordinates over the distance range. The Huo89 model provides consistent PGA predictions with the observations while it overestimates spectral ordinates over the considered distance range for the Lushan earthquake. Finally, regarding the Jiuzhaigou earthquake in Figure 7 (c), (f), and (i), the NGA-West2 and Huo89 GMMs significantly overestimate the PGA and spectral ordinates over the considered distance range. These findings are consistent with the literature in Appendix. In addition, Figure 7 seems to suggest that the magnitude scaling of the considered GMMs is well-modeled for the three considered events. However, the visual comparison of Figure 7 shows the NGA-West2 and Huo89 GMMs may require some modifications to be fully suitable for the Sichuan region. Either overestimation or underestimation of the actual ground motions may result in biased PSHA and seismic risk assessment, and consequently, inaccurate estimates of potential earthquake-induced loss (e.g., for insurance purposes, risk management, etc.).

\section{Overall GMM bias and standard deviation relative to the Sichuan data}

The previous section has introduced qualitative, visual inspection-based comparisons between the median predictions from the considered GMMs and the recent Sichuan data. This section provides a quantitative analysis of the compatibility of NGA-West2 and Huo89 GMMs to this data. The residuals between the observed data and the median predictions from each considered GMM are evaluated at eight representative periods of $0 \mathrm{~s}$ (i.e., PGA), $0.1 \mathrm{~s}, 0.2 \mathrm{~s}, 0.3 \mathrm{~s}, 0.5 \mathrm{~s}, 1.0 \mathrm{~s}, 1.5 \mathrm{~s}$, and $2.0 \mathrm{~s}$, individually. The residuals between the data and a particular GMM referred to with index $k$ are computed as in Eq. (4):

$$
\left(r_{i j}\right)_{k}=\ln \left(\mathrm{IM}_{i j}\right)_{\mathrm{obs}}-\ln \left(\mathrm{IM}_{i j}\right)_{k},
$$

where $\left(r_{i j}\right)_{k}$ is the total residual at site $j$ for the event $i$ given GMM $k$ (in natural $\log$ units); $\left(\operatorname{IM}_{i j}\right)_{\mathrm{obs}}$ is the observed IM at site $j$ for the event $i ;\left(\mathrm{IM}_{i j}\right)_{k}$ is the median prediction of IM at site $j$ for the event 
$i$ given GMM $k ; k=1, \cdots, 6$ corresponds to ASK14, BSSA14, CB14, CY14, I14, and Huo89, respectively. For simplicity, subscript $k$ will be omitted in the rest of the paper. It is worth pointing out that whether the hanging-wall effect is included or not in the considered GMM is determined based on the location of stations with respect to the hanging wall.

The analysis of residuals with respect to magnitude scaling, source-to-site distance scaling and siteeffect scaling requires the knowledge of the inter- and intra-event residuals. A linear mixed-effect regression is performed to calculate these quantities as in Eq. (5):

$$
r_{i j}=c+\eta_{i}+\varepsilon_{i j},
$$

where $c$ is the constant coefficient representing a general offset (or bias) of the selected GMM $k$ with respect to the Sichuan data; $\eta_{i}$ is the inter-event residual of the event $i$ representing the mean offset of the considered GMM to the data for event $i$ (after adjusting for mean offset $c$, which is based on all events), which is assumed to follow a normal distribution with zero mean and $\tau$ standard deviation (in natural $\log$ units); $\varepsilon_{i j}$ is the intra-event residual at site $j$ for the event $i$, which is assumed to follow a normal distribution with zero mean and $\phi$ standard deviation (in natural log units).

The average misfit between the considered GMMs and Sichuan data, denoted by the constant coefficient $c$, and its $95 \%$ confidence interval (CI) are shown in Figure 8 (a). It is shown that the predictions of the NGA-West2 and Huo89 GMMs are generally compatible with the observed PGA values and shortperiod spectral ordinates. However, there is a misfit between the predictions of these GMMs and the long-period spectral ordinates. The constant coefficient $c$ is around zero for PGA and short-period spectral ordinates while negative for long-period spectral ordinates and this trend is similar among the six GMMs. In other words, the considered GMMs produce generally consistent predictions for Sichuan data in terms of PGA and short-period spectral ordinates while these GMMs overestimate the long-period spectral ordinates. This may be due to that the estimated basin depth based on the California data do not fully reflect the basin properties in Sichuan region, particularly at long periods, where the basin effects are most pronounced. The Huo89 model gives a larger $c$ (in absolute value) with higher variability compared to the NGA-West2 GMMs, which may be due to the lack of information on various earthquake effects/regression variables in the Huo89 GMM.

[Figure 8 about here.]

Figure 8 (b), (c), and (d) present $c+\eta$ for three considered events, respectively. This quantity is equivalent to the average total residual of each event, which is defined as the inter-event residuals by Wang et al. 29, and it represents the misfit between the considered GMMs and a specific Sichuan event. Regarding the Wenchuan earthquake and the Lushan earthquake in Figure 8 (b) and (c), the six GMMs are generally consistent with the observations for PGA and short-period spectral ordinates while overestimating the long-period spectral ordinates. Regarding the Jiuzhaigou earthquake in Figure 8 (d), all six GMMs overestimate both the short- and long-period spectral ordinates across periods. The aforementioned results are consistent with the literature [e.g., 29].

The inter- and intra-event standard deviation, $\tau$ and $\phi$, versus periods and their $95 \% \mathrm{CI}$ are presented in Figure 8 (e) and (f), respectively. The estimated $\tau$ from the Sichuan dataset is around 0.5 across periods 
with large variability, which is possibly due to a limited number of events. The Huo89 gives a larger $\tau$ with higher variability than the NGA-West2 GMMs, which may be because the Huo89 GMM does not consider the style-of-faulting and other predictors, thus, has a higher variability across events. The trends of $\phi$ estimated from the Sichuan data against periods are consistent for all GMMs, however, $\phi$ is larger than expected, which may be because the information of complex earthquake effects is not available. In addition, the inter- and intra-event standard deviations predicted by the CB14 GMM given a reverse fault event in China with $M_{W}=7.0, V_{S 30}=450 \mathrm{~m} / \mathrm{s}, R_{\text {rup }}=125 \mathrm{~km}$ (i.e., the median source-to-site distance) are presented for comparison. It is shown that the results in this study follow a similar trend to the prediction; however, notable difference is observed, possibly due to the limited dataset used in this study. The aleatory variability of GMM is assumed to be dependent on magnitude, site condition (i.e., the effects of soil nonlinear response), and source-to-site distance (possibly due to "the epistemic uncertainty in regional attenuation rates" according to Abrahamson et al. [13]). Although different NGA-West2 GMMs have different assumptions and models for aleatory variability, they produce similar estimate of aleatory uncertainties and the finding mentioned above also holds for the comparisons with the predictions of ASK14, BSSA14, and CY14.

The inter-event residual $\boldsymbol{\eta}=\left(\eta_{i}\right)$ is important to study the magnitude scaling. However, because this study only considers three events and two of them have a very similar magnitude, thus, the magnitude scaling cannot be properly captured by analyzing $\boldsymbol{\eta}$. Nevertheless, the visual comparisons of Figure 7 seem to suggest the magnitude scaling is generally well-captured for the three considered events. Thus, this study will further focus on the compatibility of the considered GMMs regarding the source-to-site distance and the $V_{S 30}$-based site effect implied by the recent Sichuan data.

\section{Distance scaling}

This section assesses the considered GMMs in characterizing the source-to-site distance scaling of the Sichuan data. This is achieved by examining trends of intra-event residuals as a function of the logarithm of source-to-site distance, similarly to Scasserra et al. 43. To help illustrate trends, the linear regression as in Eq. (6) is used:

$$
\varepsilon_{i j}=a_{R}+b_{R} \ln \left(R_{i j}\right)+\widetilde{\varepsilon}_{i j},
$$

where $a_{R}$ and $b_{R}$ are the regression coefficients for the distance scaling; $R_{i j}$ is the source-to-site distance in $\mathrm{km}$ at sites $j$ for the event $i$; $\widetilde{\varepsilon}_{i j}$ is the remaining intra-event residual at site $j$ for the event $i$ that results from the fit of Eq. (6). Since I14 is applicable for "quasi-linear" sites with $V_{S 30} \geq 450 \mathrm{~m} / \mathrm{s}$, thus only 62 sites with $V_{S 30} \geq 450 \mathrm{~m} / \mathrm{s}$ are used to assess the I14 GMM. The slope parameter $b_{R}$ represents approximately the misfit of the distance scaling in the considered GMMs relative to the Sichuan dataset. The statistical $t$-test is used to study the significance level $p$ of the distance dependency in the intra-event residuals. The null hypothesis to be tested is $H_{0}: b_{R}=0$ (i.e., no bias in distance scaling). For example, if $p<0.05$ (or $1-p>0.95$ ), it is suggested there is significant evidence to reject the null hypothesis $H_{0}$ and the distance scaling of the selected GMM is biased with respect to Sichuan data.

The results of the analysis are plotted in Figure 9 together with a 95\% CI of predictions. It is shown that there is bias in the distance scaling (i.e., $1-p=>0.95$ ) of CB14 model at long periods, and that of 
Huo89 for PGA and long periods. The NGA-West2 and Huo89 GMMs with biased distance scaling give positive slope values, suggesting the decay rates with respect to distance in the Sichuan data are slower than those implied by the selected GMMs. Dangkua et al. [36] argued this may be due to the higher values of the shear-wave quality factor $Q$ for China than those implied by the GMMs. It is worth noting that the absolute values of the slope are small in general, which may be due to the limited quantity of data. These results show that the distance scalings in some NGA-West2 GMMs and Huo89 GMM need to be adjusted to better capture the observed distance dependency in the Sichuan data.

[Figure 9 about here.]

The distance scaling in most of the available GMMs represents the attenuation of seismic energy with respect to source-to-site distance $R$, which is mainly characterized by the geometrical spreading term and the anelastic term. The geometrical spreading term models the decreasing energy with increasing distance and is commonly represented as $\ln \sqrt{R^{2}+h^{2}}$, where $h$ is the fictitious depth to be estimated. The anelastic term accounts for the material anelasticity that progressively attenuate the wave energy denoted by the $R$ term. More recordings from well-recorded earthquakes available at larger distance are usually required to well constrain the anelastic term. Therefore, this study focuses on the geometrical spreading term in the considered GMMs, as shown in Table 3

[Table 3 about here.]

To further examine the misfits with respect to distance in the considered GMMs, several coefficients associated with the geometric spreading term in these GMMs are re-estimated using the Sichuan data. As shown in Table 3 the constant coefficient, the slope coefficient of the magnitude-independent geometrical spreading term and the fictitious depth are re-evaluated, including: $a_{1}, a_{2}$, and $c_{4}$ in ASK14; $e_{a}$ (additive constant term), $c_{1}$, and $h$ in BSSA14; $c_{0}, c_{5}$, and $c_{7}$ in CB14; $c_{1}, c_{4 a}$, and $c_{R B}$ in CY14; $\alpha_{11}, \alpha_{12}, \beta_{11}$, and $\beta_{12}$ in I14; $a_{0}$ and $a_{2}$ in Huo89. The other model coefficients are fixed at the published values. It is worth noting that the present study may not be well suited to determining regional adjustments on constant terms due to the limited number of events. Therefore, the results in terms of constant term should be considered with caution. The re-estimated coefficients with $95 \%$ CI are shown in Table 4 The published fictitious depth coefficients of ASK14 and CY14 are defined based on their preliminary evaluations, thus, $c_{4 M}$ in ASK14 and $c_{R B}$ in CY14 are unchanged. The fictitious depth coefficients of CB14 at long periods are fixed at published values because the re-estimation gives impractical values, possibly due to the limited events.

In addition, the changes of the standard error of the estimate (SEE) before and after the re-estimation, $\Delta s$, is provided to illustrate the improvement of model performance, which is calculated as follows,

$$
\mathrm{SEE}=\sqrt{\frac{\sum_{i} \sum_{j}\left(\varepsilon_{i j}\right)}{d f}}, \Delta s=\frac{\mathrm{SEE}_{r}-\mathrm{SEE}_{p}}{\mathrm{SEE}_{p}}
$$

where $d f$ is the degree of freedom of the considered GMM (i.e., the number of observations minus the number of parameters to be estimated in the considered GMM); subscript $r$ and $p$ correspond to the re-estimated and published GMMs, respectively. 
The model adjustments in Table 4 not only address the bias observed in the intra-event residuals (i.e., Figure 9), but also account for the general offset between the Sichuan data and NGA-West2 models (i.e., $c$ in Figure 8), particular at long periods. As shown in Table 4 , the constant coefficients, slope coefficients, and fictitious depth coefficients of NGA-West2 GMMs for short-period spectral ordinates are similar to the published values, which lie within the $95 \% \mathrm{CI}$ of the refitted values. This result shows that the refitted coefficients are not significantly different from the published values, which is consistent with the findings in Figure 9. However, for long-period spectral ordinates, the refitted coefficients of NGA-West2 GMMs are significantly different from the published values, which may be due to the general offset $c$ observed in Figure 8. Moreover, the values of $\Delta s$ show that there is an improvement in model performance before and after re-estimation when calibrating the NGA-West2 GMMs using the local data, particularly, at long periods (i.e., improved by about 20\%). Regarding Huo89 GMM, the re-estimated constant coefficients and slope coefficients are significantly different from the published values, which is again consistent with Figure 9. The $\Delta s$ values for the Huo89 show that the model performances are improved significantly, particularly at long periods.

[Table 4 about here.]

In general, the re-estimation has improved the model performance, especially for those GMMs with bias in distance scaling. Moreover, the bias in distance scaling of the newly calibrated GMMs is negligible. Thus, in the following sections, the intra-event residuals $\varepsilon_{i j}$ are re-computed using the re-estimated models and the updated intra-event residuals, denoted by $\widetilde{\varepsilon}_{i j}$, will be studied with respect to the $V_{S 30^{-}}$ based site effect.

\section{Site-effect scaling}

The scaling of ground motions with respect to the $V_{S 30}$ parameter is analyzed in this section. We examine the trends of the updated intra-event residuals (i.e., no distance bias) as a function of the logarithm of $V_{S 30}$, which is also used in Scasserra et al. [43. The linear regression as in Eq. (8) is used, similarly to the previous section:

$$
\widetilde{\varepsilon}_{i j}=a_{V}+b_{V} \ln \left(V_{S 30, i j}\right)+\epsilon_{i j}
$$

where $\widetilde{\varepsilon}_{i j}$ is the updated intra-event residual excluding the distance bias at site $j$ for the event $i$ in Eq. (6); $a_{V}$ and $b_{V}$ are the model coefficients; $\epsilon_{i j}$ is the error term.

The slope parameter $b_{V}$ represents approximately the misfit of the $V_{S 30}$ scaling in the considered GMMs with respect to the Sichuan data. The fitted trend lines of the updated intra-event residuals $\widetilde{\varepsilon}$ versus $\ln \left(V_{S 30}\right)$ are shown in Figure 10 together with $95 \%$ CI of predictions. The results show that there is statistical evidence to reject the null hypotheses $H_{0}: b_{V}=0$ (i.e., no bias in $V_{S 30}$-based site-effect scaling) at 5\% significance level for ASK14, CB14, and CY14 at long periods, for BSSA at PGA and long periods. However, I14 shows no bias in $V_{S 30}$-based site-effect scaling. These results show that the $V_{S 30}$-based site effect in some NGA-West2 GMMs need to be adjusted for the Sichuan data, in particular, for long-period spectral ordinates. The Huo89 GMM, though it is developed for soil site without site 
effect term in its functional form, shows no bias in terms of $V_{S 30}$ with respect to the Sichuan data (i.e., $1-p<0.95)$, which implies that the simplified site category may be a good proxy to partially account for the site effect.

[Figure 10 about here.]

The site condition has a strong implication on engineering applications, as it can alter the ground motion characteristics (i.e., amplitude, duration, and frequency content). The site effect in GMMs is commonly modeled by the linear site response term and the nonlinear site response term, which account for the general site effects and the complex effects due to unusual site conditions, respectively. The linear site response term is typically represented as $\ln V_{S 30}$, while the nonlinear site response term relates to the ground motions at the bedrock with a more complex functional form. To constrain the nonlinear site response term, it usually involves the 1-D analytical site response model, which is not available for the Sichuan region. Thus, this paper focuses on the linear site response term, as shown in Table 3

To address the misfit corresponding to the $V_{S 30}$-based site effect, the slope coefficients of the linear site-effect term is re-estimated. Regarding the Huo89 GMM, a $V_{S 30}$-based term (i.e., $\left.a_{5} \log \left(V_{S 30}\right)\right)$ is added to account for the site effects. It is worth noting that if there is statistically significant evidence to reject the null hypothesis that an additive constant term is equal to zero, then this constant term would be included as well. The $\Delta s$ values are provided to illustrate the improvement of the model performance. The re-estimated coefficients with $95 \%$ CI are shown in Table 5 .

[Table 5 about here.]

As shown in Table 5, the slope coefficient of the linear site response terms in NGA-West2 GMMs are similar to the published values at short periods, however, these coefficients are significantly different from the published values for long-period spectral ordinates except I14. The $\Delta s$ values of BSSA14 show that the model performance is improved by over $15 \%$ at the long period while the performance improvement for the other four NGA-West2 GMMs at long periods is around 5\%. The Huo89 GMM is generally consistent with the published value at short periods while those for moderate periods are significantly different from the published values. The $\Delta s$ of the Huo89 GMMs shows limited improvement after re-estimation at moderate periods. These results are consistent with the findings in Figure 10 . These improvements at long periods address the bias caused by the higher values of shear-wave quality factor $Q$ for China than that implied by the NGA-West2 GMMs [36]. Moreover, $\hat{c}$ results for BSSA14 obtained in this study are similar to the China results in Figure 4 of Seyhan and Stewart [50, confirming the results in this study.

\section{Conclusion}

This study investigated the compatibility of state-of-the-art NGA-West2 GMMs for shallow crustal earthquakes in active regions and the China-specific Huo89 model with the recent strong-motion data in Sichuan Province, China. The $2008 M_{w} 7.9$ Wenchuan earthquake, the $2013 M_{w} 6.6$ Lushan earthquake, and the $2017 M_{w}$ 6.5 Jiuzhaigou earthquake are considered as case-study events. This paper started with 
a brief review of several studies comparing various GMMs to Chinese ground-motion data. It is shown that the long-period spectral ordinates in Sichuan data may be overestimated by both the international and local GMMs. Moreover, it is shown that a variety of data and methods, in particular, different estimations/measurements of site conditions at the recording stations are employed in the literature, which may be due to the inadequate site information. A visual comparison of $V_{S 30}$ obtained from two estimation methods shows possible misclassification of site condition, which suggests an urgent need for detailed investigation of site characterization.

To avoid bias caused by the different horizontal ground-shaking definitions used in the considered GMMs, the RotD50 and geometric mean definitions are statistically evaluated and it is found there is no significant difference between these two definitions. Moreover, by studying the ratio between the RotD50 definition and the geometric mean definition, certain polarization in the ground motions is detected in the Sichuan data, which implies that these data should be used with caution for analyzing the structural responses of 3-D models in all orientations. Furthermore, the median ratio between the RotD50 and geometric mean definitions of the spectral ordinates is compared to the empirical model of Shahi and Baker [48, which shows the trend observed in the Sichuan data is consistent with that implied by the international model.

The visual comparisons of the observations in Sichuan data and the median predictions from the considered GMMs have shown that the magnitude scaling in each GMM is well modeled for the three case-study events. However, it is shown that the NGA-West2 and Chinese GMMs may require some modification to be suitable for the Sichuan region. Finally, a series of quantitative analyses have been performed on the inter- and intra-event residuals to assess the model performance. By using a mixed effects procedure, the results again show that the considered GMMs tend to overpredict the long-period spectral ordinates. The further study of distance dependency in the intra-event residuals has shown that CB14 and Huo89 models showed positive trend with increasing distance, implying that slower attenuation in Sichuan possibly due to the higher shear-wave quality factor $Q$ for China. Moreover, the $V_{S 30}$-based site dependency is found in some NGA-West2 models, particularly, for long-period spectral ordinates. To address the misfits corresponding to the distance scalings and the site-effect scalings in the considered GMMs with respect to the Sichuan data, the coefficients of the constant terms, the geometric spreading term and the linear site response term in these GMMs have been re-estimated and these updated GMMs generally have a better model performance in predicting Sichuan data. The updated GMMs with these minor modification can be applied for the PSHA in Sichuan Province.

While this work has focused on Sichuan Province, the presented method is applicable elsewhere in China. Future work will formally evaluate data from other regions in a manner similar to what is described here.

\section{Acknowledgements}

The authors thank two anonymous reviewers for their constructive comments, which help us to improve the manuscript. This work was supported by the China Scholarships Council [grant numbers 201608440273]. The authors acknowledge Prof. Qiang Ma, Dr. Dongwang Tao and Mr. Jilong Li from 
the Institute of Engineering Mechanics, CEA, for their support of data collection and processing. The USGS $V_{S 30}$ Models and Data is available at https://earthquake.usgs.gov/data/vs30/ (last accessed May 2018).

\section{References}

[1] Burchfiel BC, Chen Z, Liu Y. Tectonics of the Longmen Shan and adjacent regions, central China. Intern Geological Rev 1997;37(8):661-735. http://dx.doi.org/10.1080/00206819509465424.

[2] Wang W, Zhao F, Li J, Yao Z. Rupture process of the $M_{s} 8.0$ Wenchuan earthquake of Sichuan, China. Chinese J Geophys 2008;51(5):1403-10. (in Chinese).

[3] Wang W, Hao J, Yao Z. Preliminary result for rupture process of Apr. 20, 2013, Lushan earthquake, Sichuan, China. Chinese J Geophys 2013;56(4):1412-7. http://dx.doi.org/10.6038/cjg20130436; (in Chinese).

[4] Wang W, He J, Hao J, Yao Z. Preliminary result for rupture process of Aug. 8, 2017, M 7.0 earthquake, Jiuzhaigou, Sichuan, China. Tech. Rep.; Institute of Tibetan Plateau Research of Chinese Academy of Sciences; Beijing, China; 2017. http://www.itpcas.ac.cn/xwzx/zhxw/201708/ t20170809_4840737.html [accessed Dec. 2018]. (in Chinese).

[5] United Nations International Children's Emergency Fund (UNICEF) . Sichuan earthquake - one year report. Tech. Rep.; UNICEF; 2009. https://www.unicef.org/eapro/UNICEF-China_Sichuan_ Earthquake_One_Year_Report.pdf; [accessed May 2018].

[6] Wang Z. A preliminary report on the great Wenchuan earthquake. Earthq Eng Eng Vib 2008;7(2):225-34. http://dx.doi.org/10.1007/s11803-008-0856-1.

[7] World Bank . China - Wenchuan earthquake recovery project. Tech. Rep.; World Bank; Washington, D.C.; 2017. http://documents.worldbank.org/curated/en/386301488822812069/ China-Wenchuan-Earthquake-Recovery-Project; [accessed Dec. 2018].

[8] World Bank . Lushan earthquake reconstruction and risk reduction project. Tech. Rep.; World Bank; 2016. http://projects.worldbank.org/P153548?lang=en; [accessed Dec. 2018].

[9] Ren Y, Wang H, Xu P, Dhakal YP, Wen R, Ma Q, et al. Strong-motion observations of the 2017 $M_{s}$ 7.0 Jiuzhaigou earthquake: Comparison with the $2013 M_{s} 7.0$ Lushan earthquake. Seismol Res Lett 2018;89(4):1354-65. http://dx.doi.org/10.1785/0220170238.

[10] Shi J. China earthquake administration held the 2017 fourth quarter regular press conference. 2017. http://www.scio.gov.cn/xwfbh/gbwxwfbh/xwfbh/dzj/Document/1614384/1614384.htm; [accessed Dec. 2018]. (in Chinese).

[11] Wang J, Jin W, Cui YF, Zhang WF, Wu CH, Pasuto A. Earthquake-triggered landslides affecting a UNESCO Natural Site: the 2017 Jiuzhaigou earthquake in the world national park, China. J Mt Sci 2018;15(7):1412-28. http://dx.doi.org/10.1007/s11629-018-4823-7. 
[12] Li X, Zhou Z, Huang M, Wen R, Yu H, Lu D, et al. Preliminary analysis of strong-motion recordings from the magnitude 8.0 Wenchuan, China, earthquake of 12 May 2008. Seismol Res Lett 2008;79(6):844-54. http://dx.doi.org/10.1785/gssrl.79.6.844.

[13] Abrahamson NA, Silva WJ, Kamai R. Summary of the ASK14 ground motion relation for active crustal regions. Earthq Spectra 2014;30(3):1025-55. http://dx.doi.org/10.1193/070913EQS198M.

[14] Boore DM, Stewart JP, Seyhan E, Atkinson GM. NGA-West2 equations for predicting PGA, PGV, and 5\% damped PSA for shallow crustal earthquakes. Earthq Spectra 2014;30(3):1057-85. http://dx.doi.org/10.1193/070113EQS184M.

[15] Campbell KW, Bozorgnia Y. NGA-west2 ground motion model for the average horizontal components of PGA, PGV, and 5\% damped linear acceleration response spectra. Earthq Spectra 2014;30(3):1087-115. http://dx.doi.org/10.1193/062913EQS175M.

[16] Chiou BSJ, Youngs RR. Update of the Chiou and Youngs NGA model for the average horizontal component of peak ground motion and response spectra. Earthq Spectra 2014;30(3):1117-53. http://dx.doi.org/10.1193/072813EQS219M.

[17] Idriss IM. An NGA-west2 empirical model for estimating the horizontal spectral values generated by shallow crustal earthquakes. Earthq Spectra 2014;30(3):1155-77. http://dx.doi.org/10.1193/ 070613EQS195M.

[18] Huo J. Study on the near-field strong ground motion attenuation law. Phd thesis; Institute of Engineering Mechanics, China Earthquake Administration; Harbin, China; 1989. (in Chinese).

[19] Abrahamson NA, Silva WJ. Summary of the Abrahamson \& Silva NGA ground-motion relations. Earthq Spectra 2008;24(1):67-97. http://dx.doi.org/10.1193/1.2924360.

[20] Boore DM, Atkinson GM. Ground-motion prediction equations for the average horizontal component of PGA, PGV, and 5\%-damped PSA at spectral periods between $0.01 \mathrm{~s}$ and $10.0 \mathrm{~s}$. Earthq Spectra 2008;24(1):99-138. http://dx.doi.org/10.1193/1.2830434.

[21] Campbell KW, Bozorgnia Y. NGA ground motion model for the geometric mean horizontal component of PGA, PGV, PGD and 5\% damped linear elastic response spectra for periods ranging from 0.01 to 10 s. Earthq Spectra 2008;24(1):139-71. http://dx.doi.org/10.1193/1.2857546.

[22] Chiou BSJ, Youngs RR. An NGA model for the average horizontal component of peak ground motion and response spectra. Earthq Spectra 2008;24(1):173-215. http://dx.doi.org/10.1193/1.2894832.

[23] Idriss IM. An NGA empirical model for estimating the horizontal spectral values generated by shallow crustal earthquakes. Earthq Spectra 2008;24(1):217-42. http://dx.doi.org/10.1193/1.2924362.

[24] Chiou BSJ, Darragh R, Gregor N, Silva WJ. NGA project strong-motion database. Earthq Spectra 2008;24(1):23-44. http://dx.doi.org/10.1193/1.2894831. 
[25] Ancheta TD, Darragh RB, Stewart JP, Seyhan E, Silva WJ, Chiou BSJ, et al. NGA-West2 database. Earthq Spectra 2014;30(3):989-1005. http://dx.doi.org/10.1193/070913EQS197M.

[26] Douglas J, Edwards B. Recent and future developments in earthquake ground motion estimation. Earth Sci Rev 2016;160:203-19. http://dx.doi.org/10.1016/j.earscirev.2016.07.005.

[27] Kaklamanos J, Baise LG, Boore DM. Estimating unknown input parameters when implementing the NGA ground-motion prediction equations in engineering practice. Earthquake Spectra 2011;27(4):1219-35. http://dx.doi.org/10.1193/1.3650372.

[28] Li XJ, Liu L, Wang YS, Yu T. Analysis of horizontal strong-motion attenuation in the great 2008 Wenchuan earthquake. Bull Seismol Soc Am 2010;100(5 B):2440-9. http://dx.doi.org/10.1785/ 0120090245 .

[29] Wang D, Xie L, Abrahamson NA, Li S. Comparison of strong ground motion from the Wenchuan, China, earthquake of 12 May 2008 with the next generation attenuation (NGA) ground-motion models. Bull Seismol Soc Am 2010;100(5B):2381-95. http://dx.doi.org/10.1785/0120090009.

[30] Wen Z, Xie J, Gao M, Hu Y, Chau KT. Near-source strong ground motion characteristics of the 2008 Wenchuan earthquake. Bull Seismol Soc Am 2010;100(5 B):2425-39. http://dx.doi.org/10. $1785 / 0120090266$.

[31] Lu M, Li XJ, An XW, Zhao JX. A comparison of recorded response spectra from the 2008 Wenchuan, China, earthquake with modern ground-motion prediction models. Bull Seismol Soc Am 2010;100(5B):2357-80. http://dx.doi.org/10.1785/0120090303.

[32] Wen R, Ren Y. Strong-motion observations of the Lushan earthquake on 20 April 2013. Seismol Res Lett 2014;85(5):1043-55. http://dx.doi.org/10.1785/0220140006.

[33] Xie J, Li X, Wen Z, Wu C. Near-source vertical and horizontal strong ground motion from the 20 April $2013 M_{w} 6.8$ Lushan earthquake in China. Seismol Res Lett 2014;85(1):23-33. http://dx.doi.org/10.1785/0220130121.

[34] Bai Y. Comparison of strong ground motion recordings of the Lushan, China, earthquake of 20 april 2013 with the next generation attenuation (NGA)-west2 ground-motion models. Bull Seismol Soc Am 2017;107(4):1724-36. http://dx.doi.org/10.1785/0120160116

[35] Ji K, Bouaanani N, Wen R, Ren Y. Correlation of spectral accelerations for earthquakes in China. Bull Seismol Soc Am 2017;107(3):1213-26. http://dx.doi.org/10.1785/0120160291.

[36] Dangkua DT, Rong Y, Magistrale H. Evaluation of NGA-west2 and Chinese ground-motion prediction equations for developing seismic hazard maps of mainland China. Bull Seismol Soc Am 2018;108(Xx). http://dx.doi.org/10.1785/0120170186.

[37] Yu Y, Li S, Xiao L. Development of ground motion attenuation relations for the new seismic hazard map of China. Technol for Earthq Disaster Prevention 2013;8(1):24-33. 
[38] Boore DM. Orientation-independent measures of ground motion. Bull Seismol Soc Am 2006;96(4A):1502-11. http://dx.doi.org/10.1785/0120050209.

[39] Boore DM. Orientation-independent, nongeometric-mean measures of seismic intensity from two horizontal components of motion. Bull Seismol Soc Am 2010;100(4):1830-5. http://dx.doi.org/10. $1785 / 0120090400$.

[40] China Ministry of Housing and Urban-Rural Development (MOHURD) . Code for seismic design of buildings (GB 50011-2010). MOHURD; 2010.

[41] Building Seismic Safety Council (BSSC) . NEHRP recommended provisions for new buildings and other structures, Part I (Provisions) and Part II (Commentary), FEMA 368/369. Washington, D.C., USA: BSSC; 2003.

[42] Abrahamson NA, Youngs RR. A stable algorithm for regression analyses using the random effects model. Bull Seismol Soc Am 1992;82(1):505-10.

[43] Scasserra G, Stewart JP, Bazzurro P, Lanzo G, Mollaioli F. A comparison of NGA ground-motion prediction equations to Italian data. Bull Seismol Soc Am 2009;99(5):2961-78. http://dx.doi.org/10. $1785 / 0120080133$.

[44] Yu Y. Empirical estimate model for ground motion of Wenchuan earthquake zone. Phd thesis; Institute of Engineering Mechanics, China Earthquake Administration; Harbin, China; 2012. (in Chinese).

[45] Wald DJ, Allen TI. Topographic slope as a proxy for seismic site conditions and amplification. Bull Seismol Soc Am 2007;97(5):1379-95. http://dx.doi.org/10.1785/0120060267.

[46] Beyer K. Relationships between median values and between aleatory variabilities for different definitions of the horizontal component of motion. Bull Seismol Soc Am 2006;96(4A):1512-22. http://dx.doi.org/10.1785/0120050210.

[47] Barani S, Albarello D, Spallarossa D, Massa M. On the influence of horizontal ground-shaking definition on probabilistic seismic-hazard analysis. Bull Seismol Soc Am 2015;105(5):2704-12. http://dx.doi.org/10.1785/0120150033.

[48] Shahi SK, Baker JW. NGA-west2 models for ground motion directionality. Earthq Spectra 2014;30(3):1285-300. http://dx.doi.org/10.1193/040913EQS097M.

[49] Jayaram N, Baker JW. Statistical tests of the joint distribution of spectral acceleration values. Bull Seismol Soc Am 2008;98(5):2231-43. http://dx.doi.org/10.1785/0120070208.

[50] Seyhan E, Stewart JP. Semi-empirical nonlinear site amplification from NGA-West2 data and simulations. Earthq Spectra 2014;30(3):1241-56. http://dx.doi.org/10.1193/063013EQS181M. 
[51] Sadigh K, Chang CY, Egan JA, Makdisi F, Youngs RR. Attenuation relationships for shallow crustal earthquakes based on California strong motion data. Seismol Res Lett 1997;68(1):180-9. http://dx.doi.org/10.1785/gssrl.68.1.180.

[52] Fukushima O, Tanaka T. A new attenuation relation for peak horizontal acceleration of strong earthquak ground motion in Japan. Bull Seismol Soc Am 1990;80(4):757-83.

[53] Wang S, Yu Y, Gao A, Yan X. Development of attenuation relations for ground motion in China. Earthquake Research in China 2000;16(2):99-106. (in Chinese).

[54] China Ministry of Housing and Urban-Rural Development (MOHURD) . Code for seismic design of buildings (GB 50011-2001). MOHURD; 2001.

[55] Abrahamson NA, Silva WJ. Empirical response spectral attenuation relations for shallow crustal earthquakes. Seismol Res Lett 1997;68(1):94-127. http://dx.doi.org/10.1785/gssrl.68.1.94.

[56] Bozorgnia Y, Campbell KW. The vertical-to-horizontal response spectral ratio and tentative procedures for developing simplified V/H and vertical design spectra. J Earthq Eng 2004;8(2):175-207. http://dx.doi.org/10.1080/13632460409350486

[57] Loh C, Hwang C, Jean W. Seismic demand based on damage control model-considering basin effect and source effect. Soil Dyn Earthq Eng 1998;17(5):335-45. http://dx.doi.org/10.1016/ S0267-7261(98)00023-2.

[58] Bommer JJ, Stafford PJ, Alarcón JE. Empirical equations for the prediction of the significant, bracketed, and uniform duration of earthquake ground motion. Bull Seismol Soc Am 2009;99(6):3217-33. http://dx.doi.org/10.1785/0120080298.

[59] Kempton JJ, Stewart JP. Prediction equations for significant duration of earthquake ground motions considering site and near-source effects. Earthq Spectra 2006;22(4):985-1013. http://dx.doi.org/10. $1193 / 1.2358175$.

[60] Zhao JX, Irikura K, Zhang J, Fukushima Y, Somerville PG, Asano A, et al. An empirical siteclassification method for strong-motion stations in Japan using $\mathrm{H} / \mathrm{V}$ response spectral ratio. Bull Seismol Soc Am 2006;96(3):914-25. http://dx.doi.org/10.1785/0120050124.

[61] Yu Y, Wang S. Attenuation relations for horizontal peak ground acceleration and response spectrum in eastern and western China. Technol for Earthq Disaster Prevention 2006;1(3):206-17. (in Chinese).

[62] Lei JC, Gao MT, Yu YX. Seismic motion attenuation relations in Sichuan and adjacent areas. Acta Seismologica Sinica English Edition 2007;20(5):532-43. http://dx.doi.org/10.1007/ s11589-007-0532-y.

[63] Bommer JJ, Douglas J, Strasser FO. Style-of-faulting in ground-motion prediction equations. Bull Earthq Eng 2003;1(2):171-203. http://dx.doi.org/10.1023/A:1026323123154 
[64] Bindi D, Pacor F, Luzi L, Puglia R, Massa M, Ameri G, et al. Ground motion prediction equations derived from the Italian strong motion database. Bull Earthq Eng 2011;9(6):1899-920. http://dx.doi.org/10.1007/s10518-011-9313-z.

[65] Afshari K, Stewart JP. Physically parameterized prediction equations for significant duration in active crustal regions. Earthq Spectra 2016;32(4):2057-81. http://dx.doi.org/10.1193/ 063015EQS106M.

[66] Goulet CA, Bozorgnia Y, Kuehn N. NGA-east ground-motion models for the U.S. Geological Survey national seismic hazard maps. Tech. Rep.; Pacific Earthquake Engineering Research Center (PEER); 2017. https://peer.berkeley.edu/sites/default/files/christine-a-goulet-yousef-bozorgnia-2017_03_0. pdf; [accessed Dec. 2018]. 


\section{List of Figures}

$1 \quad$ (a) Distribution of recording stations and epicentres ( $t$ ) for the considered events. (b) $M_{w^{-}} R_{J B}$ distribution. The soil/rock sites are denoted by square ( $\left.\square\right) /$ cross $(+)$, respec-

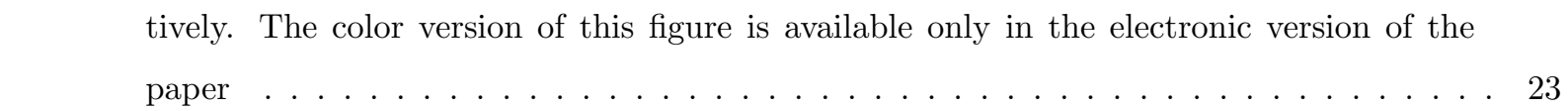

$2 \quad V_{S 30, \mathrm{Yu}}$ and $V_{S 30, \mathrm{USGS}}$ for 80 stations. The soil/rock site is shown by square (口)/cross $(+)$. The color version of this figure is available only in the electronic version of the paper. . . 23

3 The median and standard deviation of $S_{a, \text { RotD50 }} / S_{a, \mathrm{GM}}$ against the structural period $T$. . 24

4 The Q-Q plot of $\ln \left(\mathrm{IM}_{\mathrm{RotD} 50}\right)$ and $\ln \left(\mathrm{IM}_{\mathrm{GM}}\right):\left(\right.$ a) PGA; (b) $S_{a}(T=1.0) . \ldots \ldots \ldots$. . . 24

5 Displacement trace and spectral acceleration for a structural period $T=0.1 \mathrm{~s}$ in all directions computed using ground motion records from (a) Wenchuan earthquake 51GYZ

station, (b) Wenchuan earthquake 51MZQ station, (c) Lushan earthquake 51PJD station,

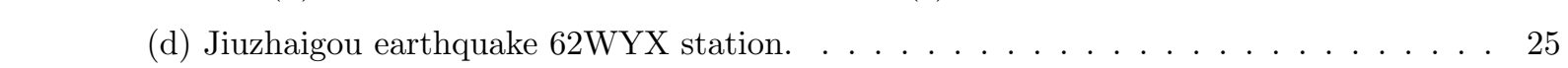

6 Median $S_{a, \text { RotD100 }} / S_{a, \text { RotD50 }}$ ratios compared with the empirical model proposed by Shahi

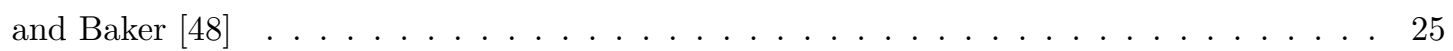

7 Comparisons between the observations and median predictions of (a-c) PGA, (d-f) $S_{a}(T=$ $0.1)$, (g-i) $S_{a}(T=1.0)$ of Wenchuan, Lushan and Jiuzhaigou earthquakes, respectively, assuming $V_{S 30}=450 \mathrm{~m} / \mathrm{s}$. The soil/rock site is denoted by square $(\square) /$ cross $(+)$, respectively. The color version of this figure is available only in the electronic version of the

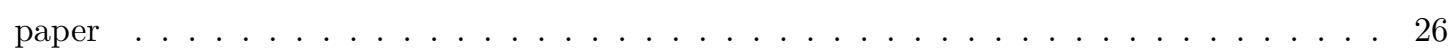

8 (a) Offset parameter $c$, (b) $c+\eta$ for Wenchuan earthquake, (c) $c+\eta$ for Lushan earthquake, (d) $c+\eta$ for Jiuzhaigou earthquake, (e) inter-event standard deviation $\tau$, (f) intra-event standard deviation $\phi$ for the six GMMs against $T$. The upper and lower bars represent the 95\% CI. The line in (e) and (f) is the standard deviation prediction of CB14 GMM given a reverse fault event in China with $M_{W}=7.0, V_{S 30}=450 \mathrm{~m} / \mathrm{s}, R_{\text {rup }}=125 \mathrm{~km}$. The color version of this figure is available only in the electronic version of the paper . . . 27

$9 \quad$ Variation of intra-event residuals against source-to-site distance for PGA, $S_{a}(T=0.1)$, $S_{a}(T=1.0)$. The color version of this figure is available only in the electronic version of

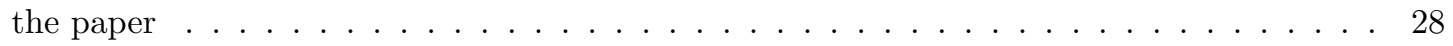

10 Variation of intra-event residuals against shear-wave velocity $V_{S 30}$ for PGA, $S_{a}(T=0.1)$, \begin{tabular}{|c|}
\hline$S_{a}(T=1.0)$. The color version of this figure is available only in the electronic version of \\
\hline
\end{tabular} the paper $\ldots \ldots \ldots \ldots \ldots \ldots$ 
(a)

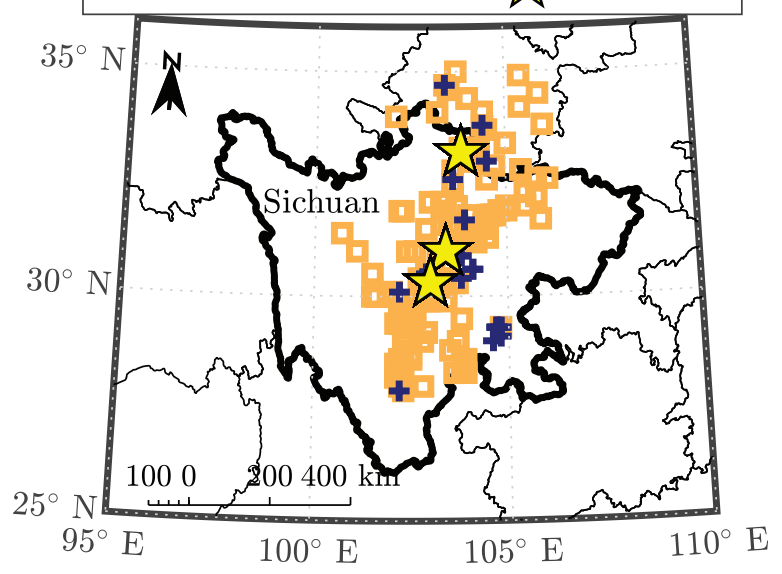

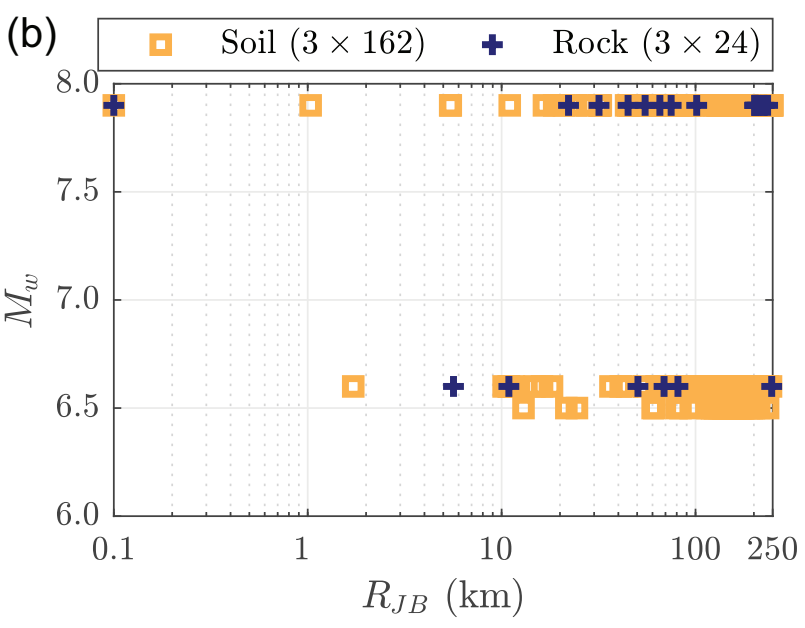

Figure 1: (a) Distribution of recording stations and epicentres ( $\downarrow$ ) for the considered events. (b) $M_{w}-R_{J B}$ distribution. The soil/rock sites are denoted by square $(\square) /$ cross $(+)$, respectively. The color version of this figure is available only in the electronic version of the paper

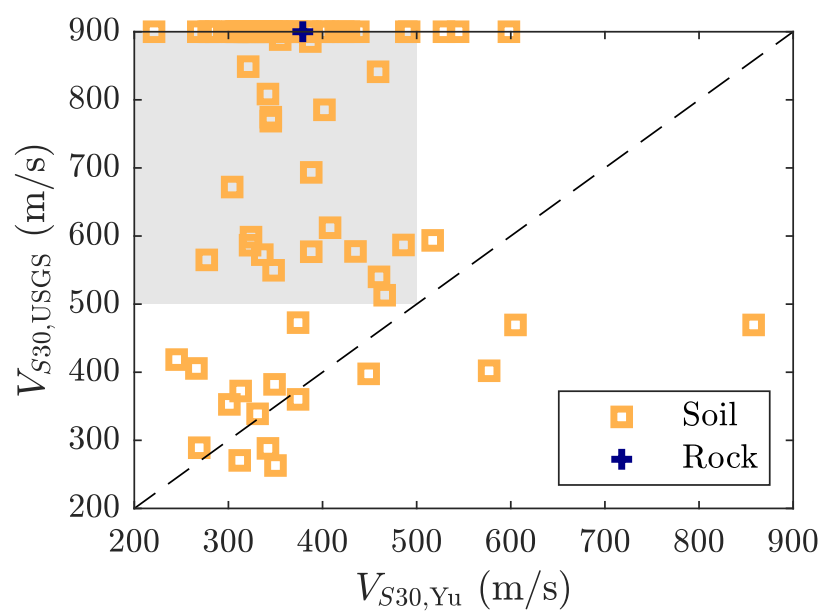

Figure 2: $V_{S 30, \mathrm{Yu}}$ and $V_{S 30, \mathrm{USGS}}$ for 80 stations. The soil/rock site is shown by square $(\square) /$ cross $(+)$. The color version of this figure is available only in the electronic version of the paper 
(a)

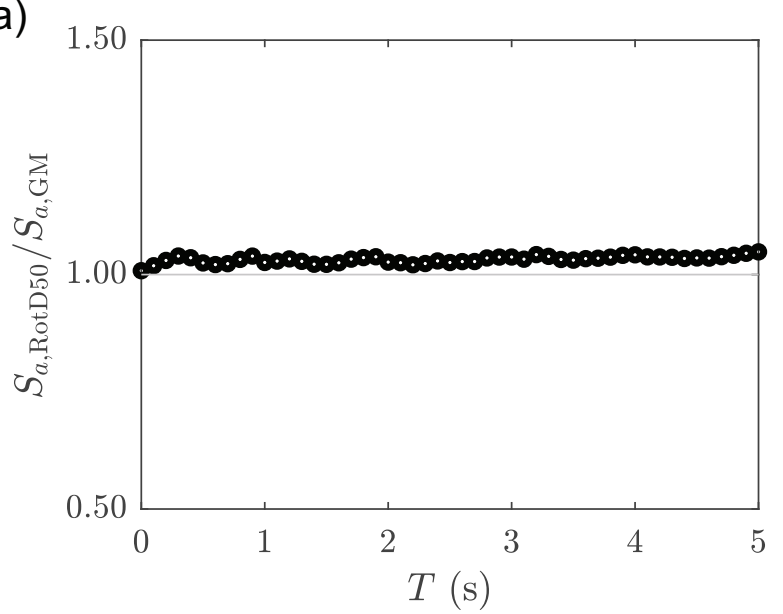

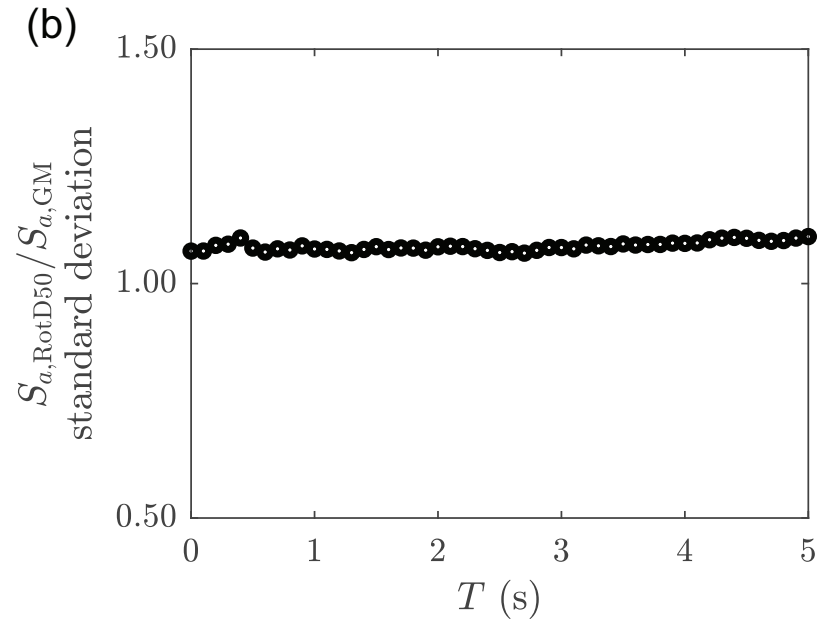

Figure 3: The median and standard deviation of $S_{a, \text { RotD50 }} / S_{a, \mathrm{GM}}$ against the structural period $T$.

(a)

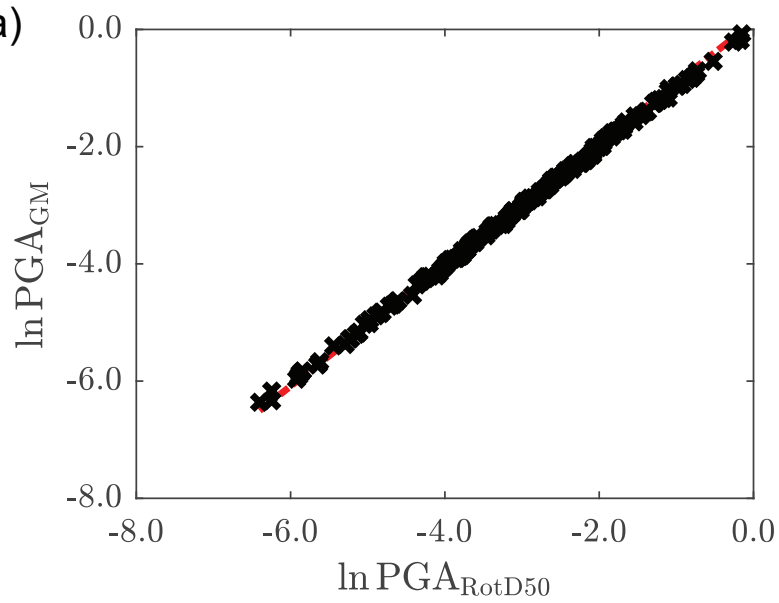

(b)

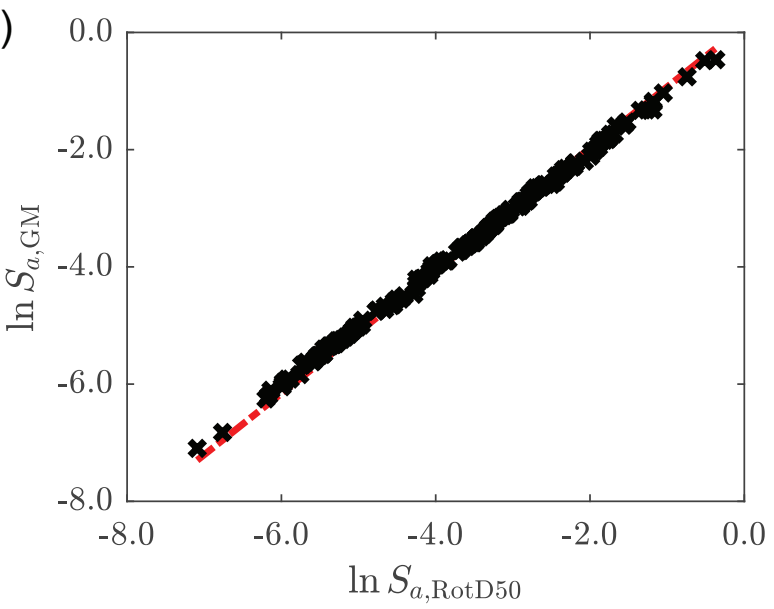

Figure 4: The Q-Q plot of $\ln \left(\mathrm{IM}_{\mathrm{RotD} 50}\right)$ and $\ln \left(\mathrm{IM}_{\mathrm{GM}}\right)$ : (a) PGA; (b) $S_{a}(T=1.0)$. 

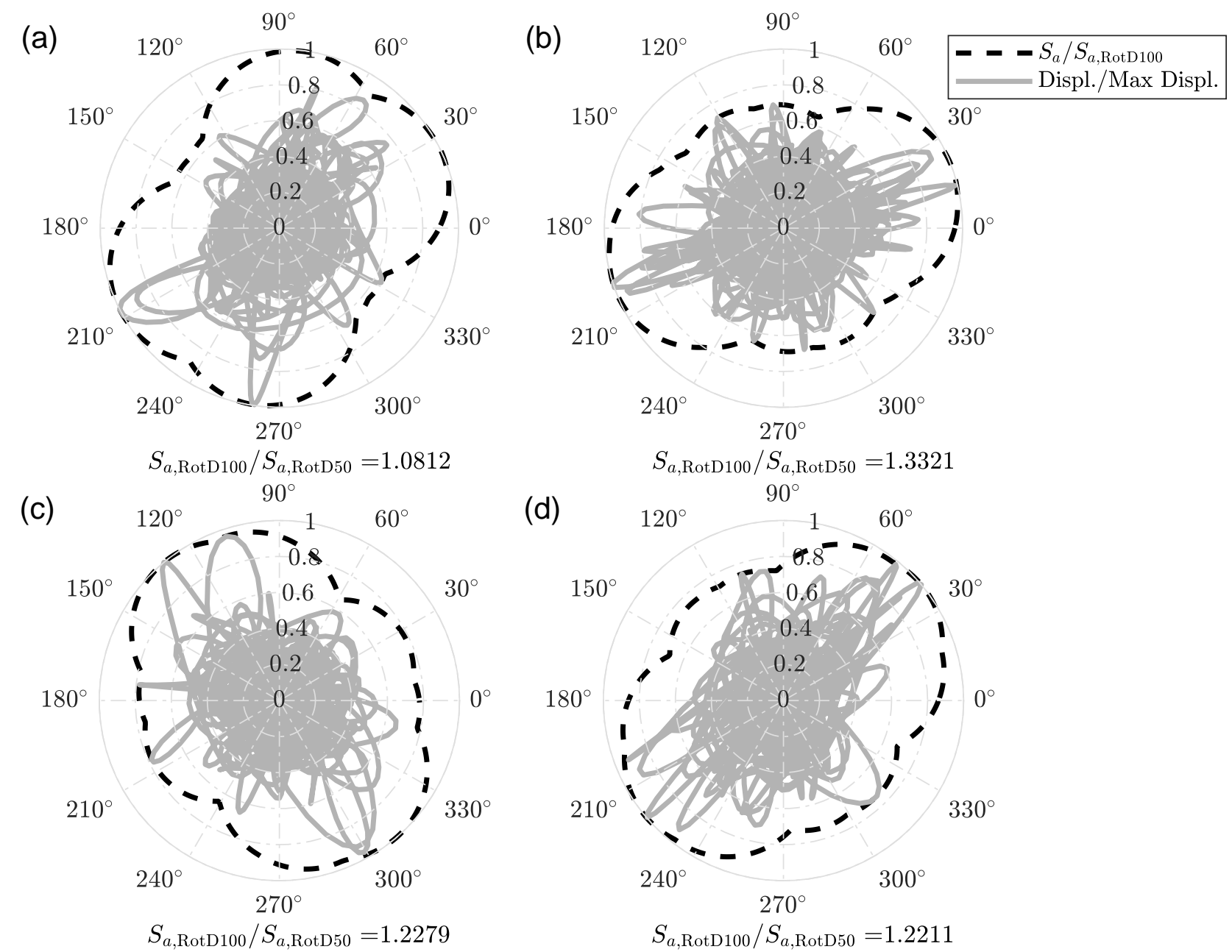

Figure 5: Displacement trace and spectral acceleration for a structural period $T=0.1 \mathrm{~s}$ in all directions computed using ground motion records from (a) Wenchuan earthquake 51GYZ station, (b) Wenchuan earthquake 51MZQ station, (c) Lushan earthquake 51PJD station, (d) Jiuzhaigou earthquake 62WYX station.

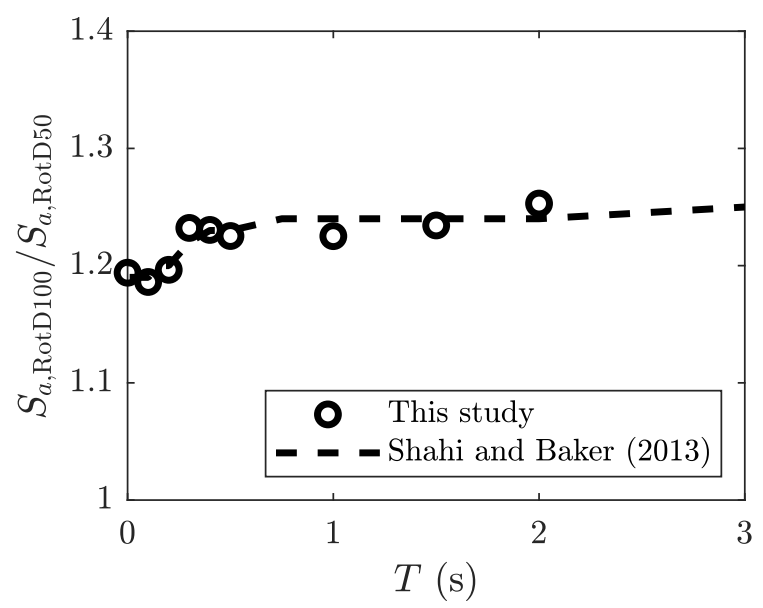

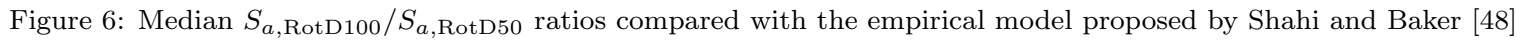




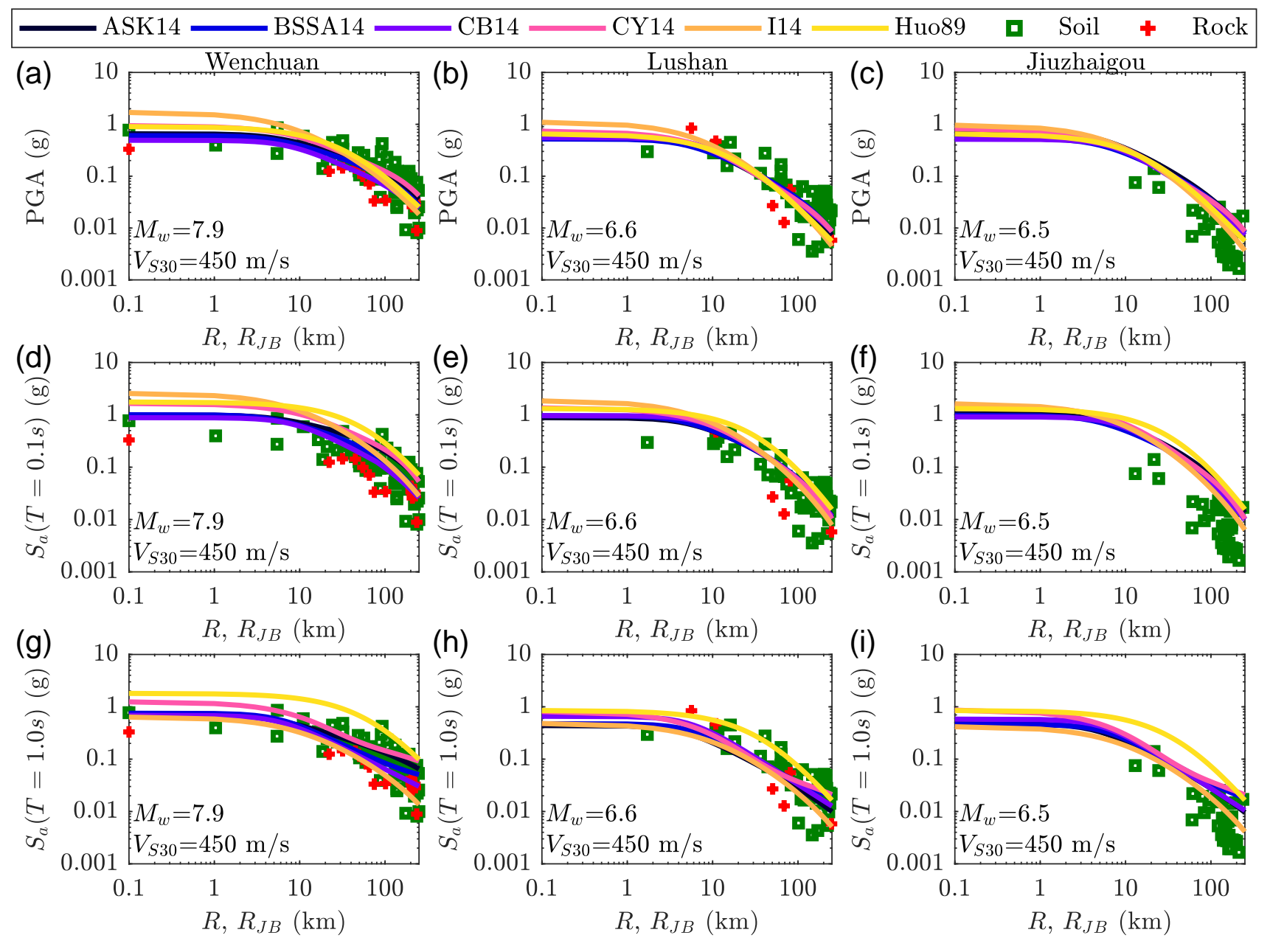

Figure 7: Comparisons between the observations and median predictions of (a-c) PGA, $(\mathrm{d}-\mathrm{f}) S_{a}(T=0.1),(\mathrm{g}-\mathrm{i}) S_{a}(T=1.0)$ of Wenchuan, Lushan and Jiuzhaigou earthquakes, respectively, assuming $V_{S 30}=450 \mathrm{~m} / \mathrm{s}$. The soil/rock site is denoted by square $(\square) /$ cross $(+)$, respectively. The color version of this figure is available only in the electronic version of the paper 
(a) 3
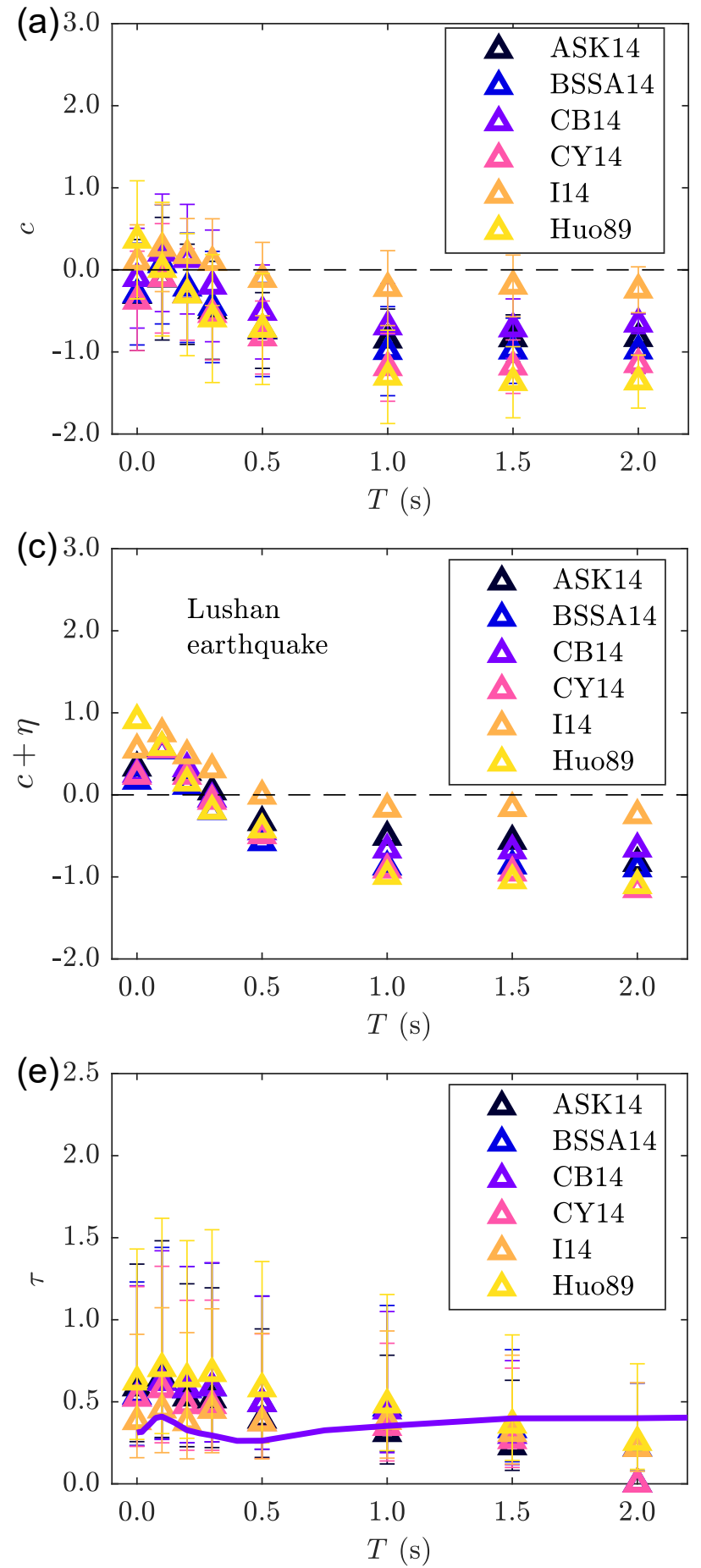
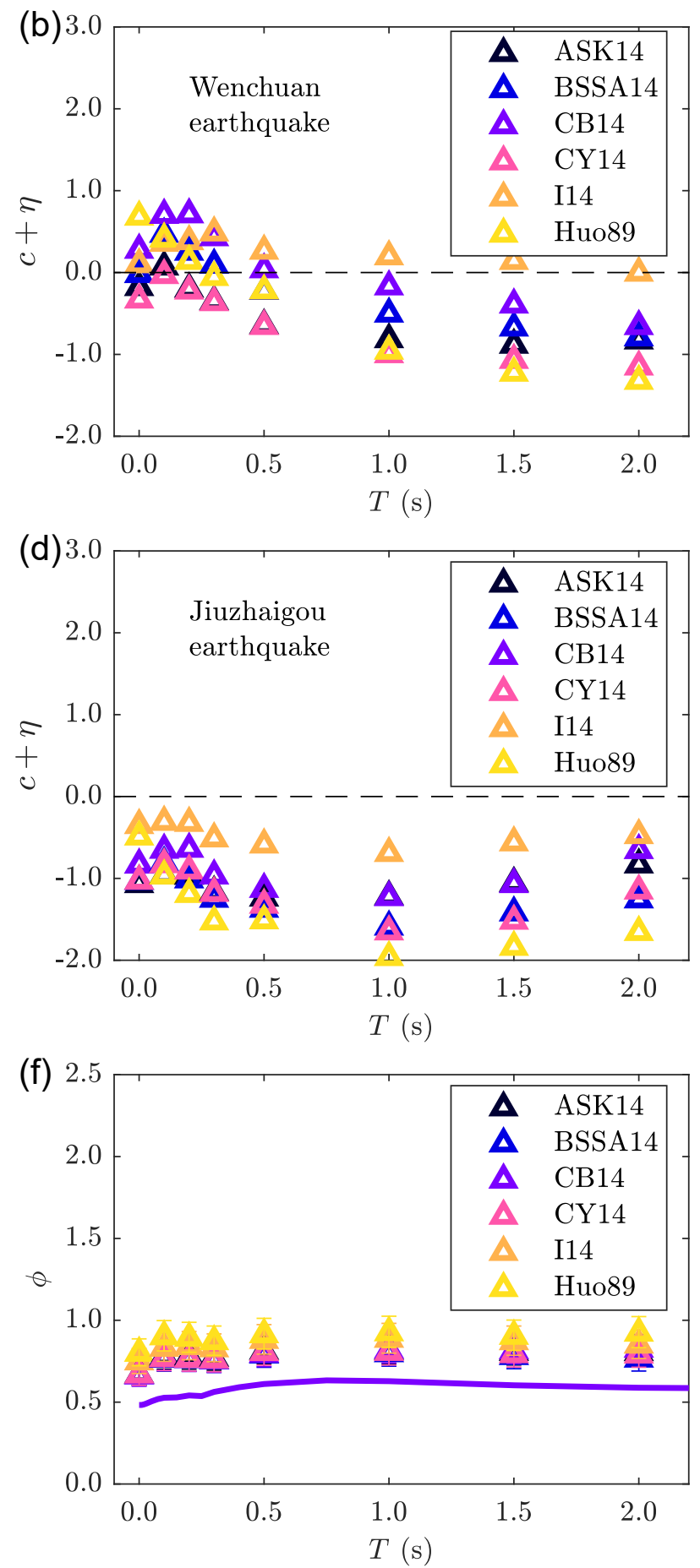

Figure 8: (a) Offset parameter $c$, (b) $c+\eta$ for Wenchuan earthquake, (c) $c+\eta$ for Lushan earthquake, (d) $c+\eta$ for Jiuzhaigou earthquake, (e) inter-event standard deviation $\tau$, (f) intra-event standard deviation $\phi$ for the six GMMs against T. The upper and lower bars represent the 95\% CI. The line in (e) and (f) is the standard deviation prediction of CB14 GMM given a reverse fault event in China with $M_{W}=7.0, V_{S 30}=450 \mathrm{~m} / \mathrm{s}, R_{r u p}=125 \mathrm{~km}$. The color version of this figure is available only in the electronic version of the paper 

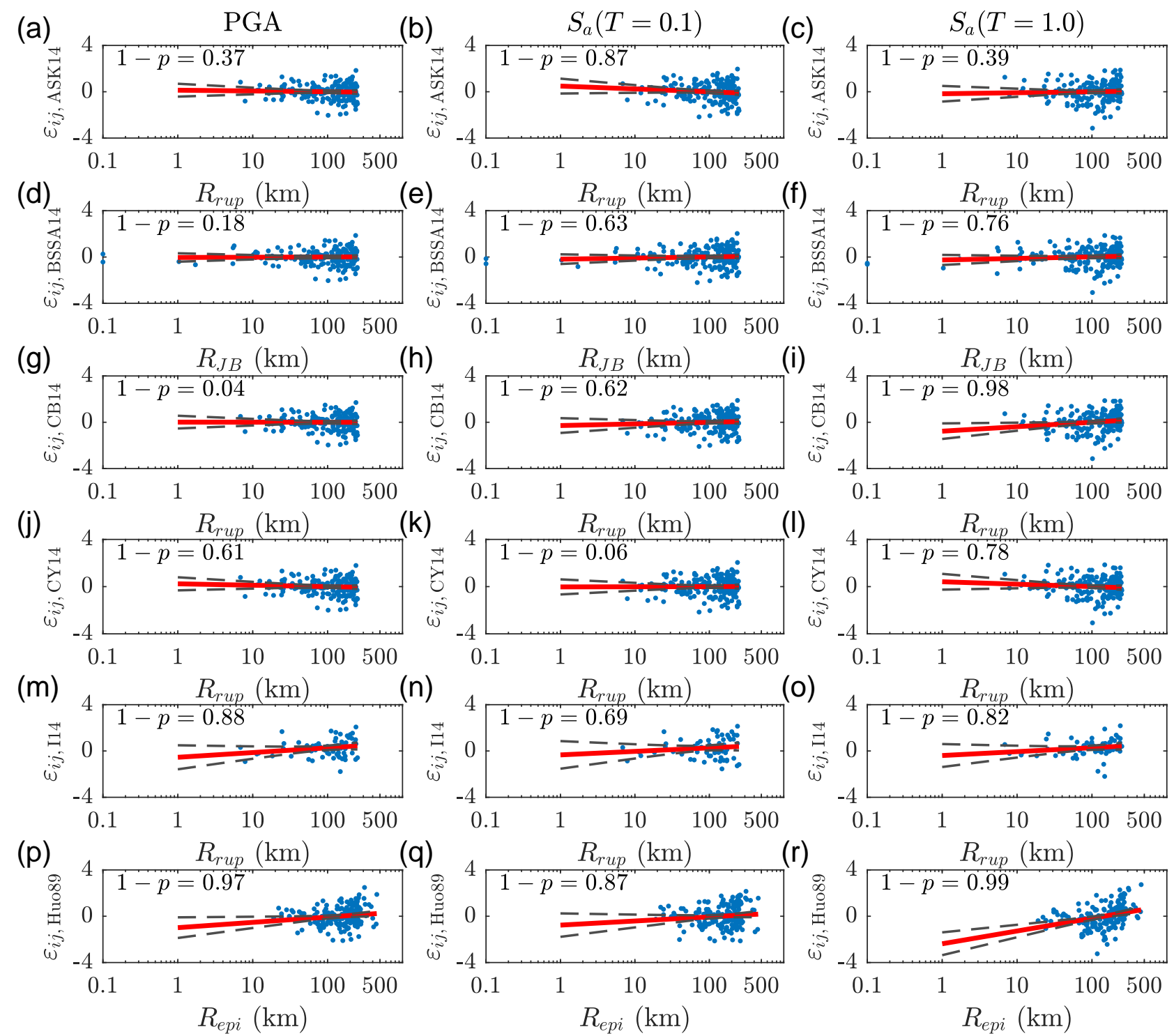

Figure 9: Variation of intra-event residuals against source-to-site distance for PGA, $S_{a}(T=0.1), S_{a}(T=1.0)$. The color version of this figure is available only in the electronic version of the paper 

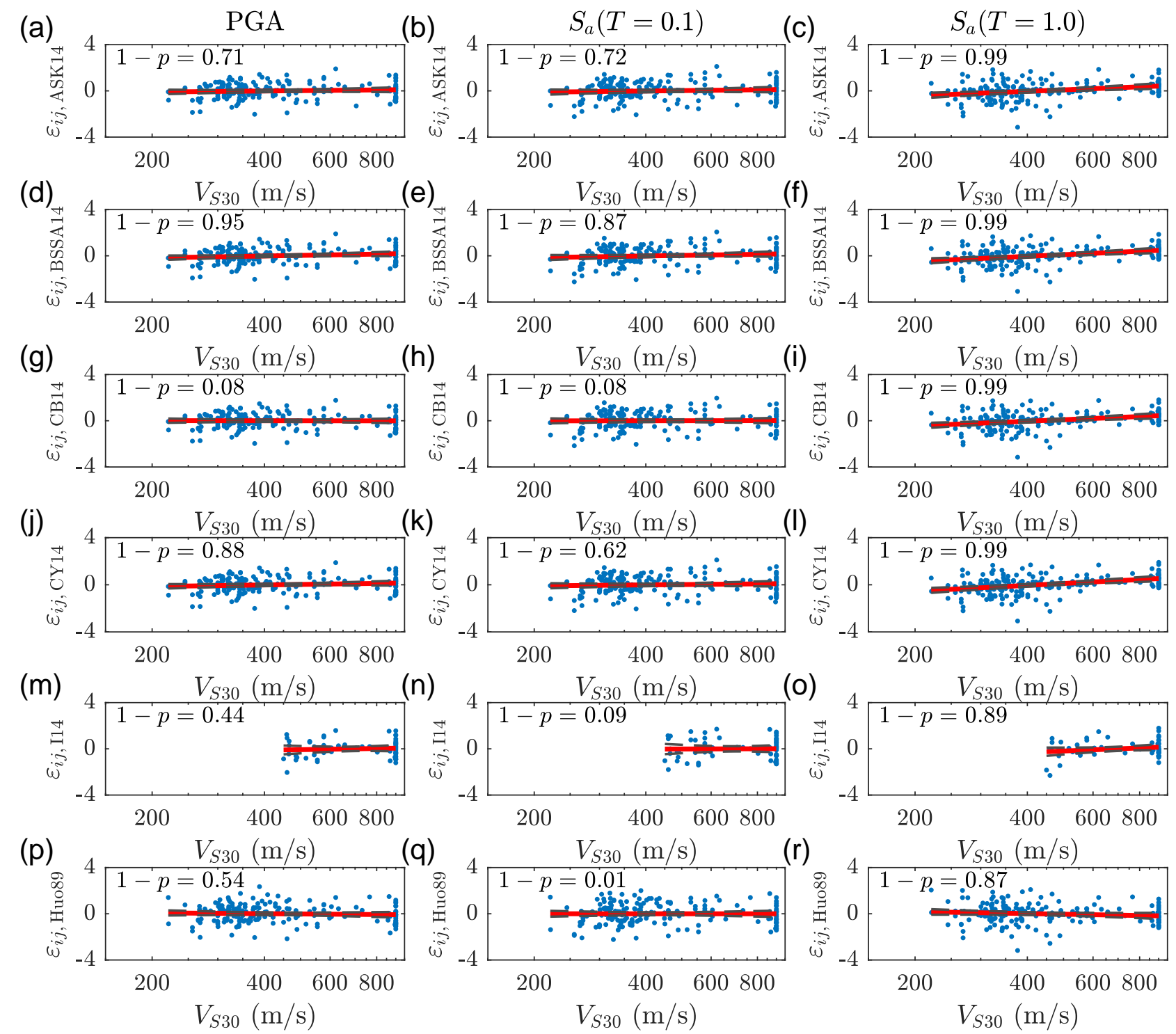

Figure 10: Variation of intra-event residuals against shear-wave velocity $V_{S 30}$ for PGA, $S_{a}(T=0.1), S_{a}(T=1.0)$. The color version of this figure is available only in the electronic version of the paper 


\section{List of Tables}

$1 \quad$ Site classification in the China Code for Seismic Design of Buildings (GB50011-2010) [40] 31

2 The metadata of selected events . . . . . . . . . . . . . . . . . . . . 31

3 The constant term, geometric spreading term, and linear site response term used in the NGA-West2 and Huo89 GMMs . . . . . . . . . . . . . . . . . . . . . . . . 32

$4 \quad$ The re-estimated coefficients of distance scaling. 'n.c.' means no change to the published value . . . . . . . . . . . . . . . . . . . . . . . 33

5 The re-estimated coefficients of site-effect scaling. 'n.c.' means no change to the published value. . . . . . . . . . . . . . . . . . . . . . . . 35

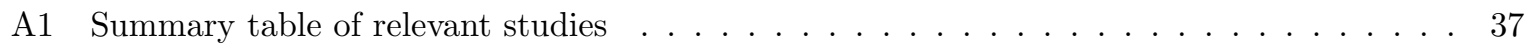


Table 1: Site classification in the China Code for Seismic Design of Buildings (GB50011-2010) 40]

\begin{tabular}{|c|c|c|c|c|c|}
\hline \multirow{2}{*}{$V_{S 20}(\mathrm{~m} / \mathrm{s})$} & $\mathrm{I}_{0}$ & $\mathrm{I}_{1}$ & II & III & IV \\
\hline & \multicolumn{5}{|c|}{ Depth of upper soil layer (m) } \\
\hline$V_{S 20}>800$ & 0 & & & & \\
\hline $500<V_{S 20} \leq 800$ & & 0 & & & \\
\hline $250<V_{S 20} \leq 500$ & & $<5$ & $\geq 5$ & & \\
\hline $150<V_{S 20} \leq 250$ & & $<3$ & $3 \sim 50$ & $>50$ & \\
\hline$V_{S 20} \leq 150$ & & $<3$ & $3 \sim 15$ & $15 \sim 80$ & $>80$ \\
\hline
\end{tabular}

Table 2: The metadata of selected events

\begin{tabular}{|c|c|c|c|c|c|c|c|c|c|c|c|}
\hline Event & $\begin{array}{l}\text { Date and } \\
\text { local time }\end{array}$ & $\begin{array}{l}\text { Latitude } \\
\qquad\left({ }^{\circ} N\right)\end{array}$ & $\begin{array}{l}\text { Longitude } \\
\qquad\left({ }^{\circ} E\right)\end{array}$ & $\begin{array}{l}\text { Depth } \\
(\mathrm{km})\end{array}$ & $\begin{array}{l}\text { Faule } \\
\text { style }\end{array}$ & $M_{w}$ & $\begin{array}{l}\text { Strike } \\
\left(\left(^{\circ}\right)\right.\end{array}$ & $\begin{array}{l}\text { Dip } \\
\left(^{\circ}\right)\end{array}$ & $\begin{array}{c}\text { Rake } \\
\left(^{\circ}\right)\end{array}$ & $\begin{array}{l}\text { Length } \\
(\mathrm{km})\end{array}$ & $\begin{array}{c}\text { Width } \\
(\mathrm{km})\end{array}$ \\
\hline Wenchuana & $\begin{array}{c}2008.05 .12 \\
14: 28: 04\end{array}$ & 31.0 & 103.4 & 14 & Reverse & 7.9 & 229.4 & 32.0 & 118.3 & 308 & 40 \\
\hline Lushan & $\begin{array}{c}2013.04 .20 \\
\text { 08:02:46 }\end{array}$ & 30.3 & 103.0 & 13 & Reverse & 6.6 & 205.0 & 38.5 & 88.8 & 66 & 35 \\
\hline Jiuzhaigou $^{\mathbb{C}}$ & $\begin{array}{c}2017.08 .08 \\
21: 19: 46\end{array}$ & 33.2 & 103.8 & 20 & Strike-slip & 6.5 & 148.5 & 68.9 & -3.1 & 57 & 27 \\
\hline
\end{tabular}

\footnotetext{
a The finite-fault model is obtained from Wang et al. [2], 93 three-component records with $R_{J B} \leq 250 \mathrm{~km}$;

b The finite-fault model is obtained from Wang et al. [3], 59 three-component records with $R_{J B} \leq 250 \mathrm{~km}$;

c The finite-fault model is obtained from Wang et al. [4], 34 three-component records with $R_{J B} \leq 250 \mathrm{~km}$.
} 
Table 3: The constant term, geometric spreading term, and linear site response term used in the NGA-West2 and Huo89 GMMs

\begin{tabular}{|c|c|c|c|c|}
\hline GMMs & Constant term & Geometric spreading term & Linear site response term & \\
\hline ASK14 & $a_{1}$ & $\begin{array}{l} \begin{cases}{\left[a_{2}+a_{3}\left(M_{w}-M_{1}\right)\right] \ln (R)} & M_{w} \geq 5.0 \\
{\left[a_{2}+a_{3}\left(5.0-M_{1}\right)\right] \ln (R)} & M_{w}<5.0\end{cases} \\
\text { where } R=\sqrt{R_{r u p}^{2}+c_{4 M}^{2}} \\
c_{4 M}= \begin{cases}c_{4} & M_{w}>5 \\
c_{4}-\left(c_{4}-1\right)\left(5-M_{w}\right) & 4<M_{w} \leq 5 \\
1 & M_{w} \leq 4\end{cases} \end{array}$ & $\begin{array}{l}a_{10} \ln \left(V_{S 30}^{*} / V_{\text {Lin }}\right) \\
\text { where } V_{S 30}^{*}= \begin{cases}V_{S 30} & V_{S 30}<V_{1} \\
V_{1} & V_{S 30} \geq V_{1}\end{cases} \\
V_{1}= \\
\left\{\begin{array}{l}1500 \\
\exp \left[-0.35 \ln \left(\frac{T}{0.5}\right)+\ln 1500\right] \\
800\end{array}\right.\end{array}$ & $\begin{array}{l}T \leq 0.5 \\
0.5<T<3 \\
T \geq 3\end{array}$ \\
\hline BSSA14 & none & {$\left[c_{1}+c_{2}\left(M_{w}-4.5\right)\right] \ln \left(\sqrt{R_{J B}^{2}+h^{2}} / 1.0\right)$} & $\begin{cases}c \ln \left(\frac{V_{S 30}}{760}\right) & V_{S 30} \leq V_{c} \\
c \ln \left(\frac{V_{c}}{760}\right) & V_{S 30}>V_{c}\end{cases}$ & \\
\hline $\mathrm{CB} 14$ & $c_{0}$ & $\left(c_{5}+c_{6} M_{w}\right) \ln \left(\sqrt{R_{r u p}^{2}+c_{7}^{2}}\right)$ & $c_{11} \ln \left(\frac{V_{S 30}}{k_{1}}\right)$ & \\
\hline CY14 & $c_{1}$ & $\begin{array}{l}c_{4} \ln \left\{R_{\text {rup }}+c_{5} \cosh \left[c_{6} \max \left(M_{w}-c_{H M}, 0\right)\right]\right\} \\
+\left(c_{4 a}+c_{4}\right) \ln \left(\sqrt{R_{r u p}^{2}+c_{R B}^{2}}\right)\end{array}$ & $\phi_{1} \min \left[\ln \left(\frac{V_{S 30}}{1130}\right), 0\right]$ & \\
\hline $\mathrm{I} 14$ & $\begin{cases}\alpha_{11} & M_{w} \leq 6.75 \\
\alpha_{12} & M_{w}>6.75\end{cases}$ & $\begin{array}{ll}\left(\beta_{11}+\beta_{21} M_{w}\right) \ln \left(R_{\text {rup }}+10\right) & M_{w} \leq 6.75 \\
\left(\beta_{12}+\beta_{22} M_{w}\right) \ln \left(R_{\text {rup }}+10\right) & M_{w}>6.75\end{array}$ & $\xi \ln \left(V_{S 30}\right)$ & \\
\hline Huo89 & $a_{0}$ & $a_{2} \log \left[R_{e p i}+a_{3} \exp \left(a_{4} M_{s}\right)\right]$ & none & \\
\hline
\end{tabular}


Table 4: The re-estimated coefficients of distance scaling. 'n.c.' means no change to the published value.

\begin{tabular}{|c|c|c|c|c|c|c|c|c|c|c|c|}
\hline \multirow{2}{*}{ GMMs } & \multirow{2}{*}{$T(\mathrm{~s})$} & \multicolumn{3}{|c|}{ Constant } & \multicolumn{3}{|c|}{ Slope } & \multicolumn{3}{|c|}{ Fictitious depth } & \multirow{2}{*}{$\begin{array}{c}\Delta s^{\mathrm{b}} \\
(\%)\end{array}$} \\
\hline & & Published & Refitted & $\pm \mathrm{CI}^{\mathrm{a}}$ & Published & Refitted & $\pm \mathrm{CI}$ & Published & Refitted & $\pm \mathrm{CI}$ & \\
\hline \multirow{6}{*}{ ASK14 } & & $a_{1}$ & $\hat{a}_{1}$ & & $a_{2}$ & $\hat{a}_{2}$ & & $c_{4}$ & $\hat{c}_{4}$ & & \\
\hline & PGA & 0.587 & 0.846 & 0.762 & -0.790 & -0.888 & 0.162 & 4.500 & n.c. & - & -2 \\
\hline & 0.1 & 1.169 & 2.335 & 1.002 & -0.790 & -1.032 & 0.210 & 4.500 & n.c. & - & -1 \\
\hline & 0.5 & 1.571 & 0.969 & 0.751 & -0.790 & -0.803 & 0.162 & 4.500 & n.c. & - & -20 \\
\hline & 1 & 1.043 & 0.179 & 0.731 & -0.790 & -0.776 & 0.157 & 4.500 & n.c. & - & -27 \\
\hline & 2 & 0.329 & -0.877 & 0.685 & -0.790 & -0.709 & 0.147 & 4.500 & n.c. & - & -31 \\
\hline \multirow{6}{*}{ BSSA14 } & & $e_{a}$ & $\hat{e}_{a}$ & & $c_{1}$ & $\hat{c}_{1}$ & & $h$ & $\hat{h}$ & & \\
\hline & PGA & 0 & 0.130 & 0.858 & -1.134 & -1.196 & 0.180 & 4.500 & 4.846 & 8.581 & -2 \\
\hline & 0.1 & 0 & 0.408 & 0.945 & -1.065 & -1.103 & 0.199 & 4.130 & 5.024 & 10.002 & -17 \\
\hline & 0.5 & 0 & -0.749 & 0.825 & -1.146 & -1.109 & 0.176 & 5.340 & 3.701 & 6.070 & -2 \\
\hline & 1 & 0 & -0.765 & 1.013 & -1.193 & -1.207 & 0.212 & 5.740 & 7.287 & 9.288 & -21 \\
\hline & 2 & 0 & -1.132 & 0.880 & -1.216 & -1.167 & 0.185 & 6.540 & 7.178 & 8.304 & -55 \\
\hline \multirow{6}{*}{ CB14 } & & $c_{0}$ & $\hat{c}_{0}$ & & $c_{5}$ & $\hat{c}_{5}$ & & $c_{7}$ & $\hat{c}_{7}$ & & \\
\hline & PGA & -4.416 & -3.838 & 1.165 & -2.773 & -2.882 & 0.239 & 6.768 & 8.975 & 17.653 & -1 \\
\hline & 0.1 & -3.666 & -2.506 & 1.556 & -2.633 & -2.783 & 0.315 & 7.294 & 15.999 & 18.949 & -9 \\
\hline & 0.5 & -8.379 & -8.921 & 1.147 & -2.296 & -2.249 & 0.238 & 6.902 & 6.530 & 22.927 & -6.0 \\
\hline & 1 & -11.011 & -12.080 & 0.786 & -2.158 & -2.039 & 0.169 & 5.650 & n.c. & - & -13.6 \\
\hline & 2 & -12.969 & -14.701 & 0.698 & -2.104 & -1.869 & 0.150 & 6.632 & n.c. & - & -23.7 \\
\hline \multirow{7}{*}{ CY14 } & & $c_{1}$ & $\hat{c}_{1}$ & & $c_{4 a}$ & $\hat{c}_{4 a}$ & & $c_{R B}$ & $\hat{c}_{R B}$ & & \\
\hline & PGA & -1.507 & -1.059 & 1.179 & -0.500 & -0.653 & 0.243 & 50.000 & n.c. & - & -6 \\
\hline & 0.1 & -0.561 & 0.022 & 1.425 & -0.500 & -0.619 & 0.292 & 50.000 & n.c. & - & 0 \\
\hline & 0.5 & -1.651 & -2.665 & 1.265 & -0.500 & -0.446 & 0.261 & 50.000 & n.c. & - & -23 \\
\hline & 1 & -2.537 & -2.940 & 1.221 & -0.500 & -0.647 & 0.252 & 50.000 & n.c. & - & -38 \\
\hline & 2 & -3.415 & -4.036 & 1.118 & -0.500 & -0.612 & 0.231 & 50.000 & n.c. & - & -43 \\
\hline & & $\alpha_{11} / \alpha_{12}$ & $\hat{\alpha}_{11} / \hat{\alpha}_{12}$ & & $\beta_{11} / \beta_{12}$ & $\hat{\beta}_{11} / \hat{\beta}_{12}$ & & & & & \\
\hline
\end{tabular}


Table 4: continued from previous page

\begin{tabular}{|c|c|c|c|c|c|c|c|c|c|c|c|}
\hline \multirow{2}{*}{ GMMs } & \multirow{2}{*}{$T(\mathrm{~s})$} & \multicolumn{3}{|c|}{ Constant } & \multicolumn{3}{|c|}{ Slope } & \multicolumn{3}{|c|}{ Fictitious depth } & \multirow{2}{*}{$\begin{array}{c}\Delta s^{\mathrm{b}} \\
(\%)\end{array}$} \\
\hline & & Published & Refitted & $\pm \mathrm{CI}^{\mathrm{a}}$ & Published & Refitted & $\pm \mathrm{CI}$ & Published & Refitted & $\pm \mathrm{CI}$ & \\
\hline & \multirow{2}{*}{ PGA } & 7.089 & 7.110 & 1.805 & 2.994 & 2.893 & 0.379 & \multirow{2}{*}{ - } & \multirow{2}{*}{-} & \multirow{2}{*}{ - } & \multirow{2}{*}{-11.2} \\
\hline & & 9.014 & 9.107 & 2.520 & 2.949 & 2.949 & 0.542 & & & & \\
\hline & \multirow{2}{*}{0.1} & 7.579 & 8.102 & 2.088 & 3.019 & 2.994 & 0.439 & \multirow{2}{*}{ - } & \multirow{2}{*}{ - } & \multirow{2}{*}{-} & \multirow{2}{*}{-15.1} \\
\hline & & 9.425 & 10.250 & 2.915 & 2.874 & 2.874 & 0.627 & & & & \\
\hline & \multirow{2}{*}{0.5} & 9.214 & 8.038 & 1.726 & 2.856 & 2.592 & 0.363 & \multirow{2}{*}{ - } & \multirow{2}{*}{-} & \multirow{2}{*}{-} & \multirow{2}{*}{-5.8} \\
\hline & & 11.448 & 11.852 & 2.411 & 2.351 & 2.351 & 0.518 & & & & \\
\hline & \multirow{2}{*}{1} & 7.045 & 6.314 & 1.565 & 2.734 & 2.601 & 0.329 & \multirow{2}{*}{-} & \multirow{2}{*}{-} & \multirow{2}{*}{-} & \multirow{2}{*}{-7.9} \\
\hline & & 9.857 & 9.948 & 2.185 & 2.068 & 2.068 & 0.470 & & & & \\
\hline \multirow{2}{*}{$\mathrm{I} 14$} & \multirow{2}{*}{2} & 3.361 & 1.793 & 1.474 & 2.684 & 2.377 & 0.310 & \multirow{2}{*}{ - } & \multirow{2}{*}{ - } & \multirow{2}{*}{-} & \multirow{2}{*}{-4.7} \\
\hline & & 6.866 & 6.967 & 2.059 & 1.994 & 1.994 & 0.443 & & & & \\
\hline \multirow{6}{*}{ Huo89 } & & $a_{0}$ & $\hat{a}_{0}$ & & $a_{2}$ & $\hat{a}_{2}$ & & & & & \\
\hline & PGA & 0.163 & -0.202 & 0.601 & -1.842 & -1.576 & 0.266 & - & - & - & -14 \\
\hline & 0.1 & 1.700 & 0.997 & 0.849 & -2.456 & -2.116 & 0.361 & - & - & - & -3 \\
\hline & 0.5 & 1.219 & -0.895 & 0.775 & -2.135 & -1.328 & 0.330 & - & - & - & -16 \\
\hline & 1 & 0.152 & -2.338 & 0.733 & -2.104 & -1.251 & 0.313 & - & - & - & -39 \\
\hline & 2 & -1.209 & -3.782 & 0.669 & -2.193 & -1.332 & 0.287 & - & - & - & -46 \\
\hline
\end{tabular}

b $\Delta s$ is the changes of the standard error of the estimate (SEE) before and after the re-estimation. 
Table 5: The re-estimated coefficients of site-effect scaling. 'n.c.' means no change to the published value.

\begin{tabular}{|c|c|c|c|c|c|c|c|c|}
\hline \multirow{2}{*}{ GMMs } & \multirow{2}{*}{$T(\mathrm{~s})$} & \multicolumn{3}{|c|}{ Constant } & \multicolumn{3}{|c|}{ Slope } & \multirow{2}{*}{$\begin{array}{c}\Delta s^{\mathrm{b}} \\
(\%)\end{array}$} \\
\hline & & Published & Refitted & $\pm \mathrm{CI}^{\mathrm{a}}$ & Published & Refitted & $\pm \mathrm{CI}$ & \\
\hline \multirow{6}{*}{ ASK14 } & & $\Delta a_{1}$ & $\Delta \hat{a}_{1}$ & & $a_{10}$ & $\hat{a}_{10}$ & & \\
\hline & PGA & 0 & n.c. & - & 1.735 & 1.743 & 0.196 & 0 \\
\hline & 0.1 & 0 & n.c. & - & 1.310 & 1.311 & 0.153 & 0 \\
\hline & 0.5 & 0 & n.c. & - & 4.450 & 4.764 & 0.270 & -1 \\
\hline & 1 & 0 & n.c. & - & 4.300 & 4.652 & 0.255 & -2 \\
\hline & 2 & 0 & -0.147 & 0.134 & 0.550 & 1.111 & 0.282 & -4 \\
\hline \multirow{6}{*}{ BSSA14 } & & $\Delta e_{a}$ & $\Delta \hat{e}_{a}$ & & $c$ & $\hat{c}$ & & \\
\hline & PGA & 0 & n.c. & - & -0.600 & -0.575 & 0.165 & 0 \\
\hline & 0.1 & 0 & n.c. & - & -0.487 & -0.486 & 0.191 & 0 \\
\hline & 0.5 & 0 & n.c. & - & -0.969 & -0.884 & 0.186 & -24 \\
\hline & 1 & 0 & n.c. & - & -1.050 & -0.663 & 0.183 & -16 \\
\hline & 2 & 0 & n.c. & - & -1.039 & -0.410 & 0.158 & -18 \\
\hline \multirow{6}{*}{ CB14 } & & $\Delta c_{0}$ & $\Delta \hat{a}_{0}$ & & $c_{11}$ & $\hat{c}_{11}$ & & \\
\hline & PGA & 0 & n.c. & - & 1.090 & 1.037 & 0.139 & 0 \\
\hline & 0.1 & 0 & n.c. & - & 1.615 & 1.578 & 0.139 & 0 \\
\hline & 0.5 & 0 & n.c. & - & 2.355 & 2.525 & 0.328 & 0 \\
\hline & 1 & 0 & n.c. & - & 1.447 & 1.808 & 0.324 & -1 \\
\hline & 2 & 0 & n.c. & - & -0.514 & -0.018 & 0.281 & -3 \\
\hline \multirow{6}{*}{ CY14 } & & $\Delta c_{1}$ & $\Delta \hat{c}_{1}$ & & $\phi_{1}$ & $\hat{\phi}_{1}$ & & \\
\hline & PGA & 0 & n.c. & - & -0.521 & -0.504 & 0.110 & 0 \\
\hline & 0.1 & 0 & n.c. & - & -0.444 & -0.440 & 0.125 & -10 \\
\hline & 0.5 & 0 & 0.422 & 0.325 & -1.004 & -0.568 & 0.310 & -2 \\
\hline & 1 & 0 & 0.593 & 0.314 & -1.094 & -0.481 & 0.300 & -4 \\
\hline & 2 & 0 & 0.669 & 0.284 & -1.115 & -0.425 & 0.271 & -6 \\
\hline
\end{tabular}


Table 5: continued from previous page

\begin{tabular}{|c|c|c|c|c|c|c|c|c|}
\hline \multirow{2}{*}{ GMMs } & \multirow{2}{*}{$T(\mathrm{~s})$} & \multicolumn{3}{|c|}{ Constant } & \multicolumn{3}{|c|}{ Slope } & \multirow{2}{*}{$\begin{array}{c}\Delta s^{\mathrm{b}} \\
(\%)\end{array}$} \\
\hline & & Published & Refitted & $\pm \mathrm{CI}^{\mathrm{a}}$ & Published & Refitted & $\pm \mathrm{CI}$ & \\
\hline \multirow{6}{*}{$\mathrm{I} 14$} & & $\Delta \alpha$ & $\Delta \hat{\alpha}$ & & $\xi$ & $\hat{\xi}$ & & \\
\hline & PGA & 0 & n.c. & - & -0.854 & -0.854 & 0.032 & 0 \\
\hline & 0.1 & 0 & n.c. & - & -0.757 & -0.758 & 0.038 & 0 \\
\hline & 0.5 & 0 & n.c. & - & -1.023 & -1.022 & 0.031 & 0 \\
\hline & 1 & 0 & n.c. & - & -1.009 & -1.008 & 0.028 & 0 \\
\hline & 2 & 0 & n.c. & - & -0.851 & -0.850 & 0.026 & 0 \\
\hline \multirow{3}{*}{ Huo89 } & & $\Delta a_{0}$ & $\Delta \hat{a}_{0}$ & & $a_{5}$ & $\hat{a}_{5}$ & & \\
\hline & PGA & 0 & n.c. & - & 0 & -0.001 & 0.022 & 0 \\
\hline & 0.1 & 0 & n.c. & - & 0 & -0.001 & 0.025 & 0 \\
\hline \multirow{3}{*}{ Huo89 } & 0.5 & 0 & 1.198 & 0.928 & 0 & -0.455 & 0.352 & -2 \\
\hline & 1 & 0 & 0.952 & 0.895 & 0 & -0.362 & 0.339 & -1 \\
\hline & 2 & 0 & n.c. & - & 0 & -0.001 & 0.021 & 0 \\
\hline
\end{tabular}

b $\Delta s$ is the changes of the standard error of the estimate (SEE) before and after the re-estimation. 


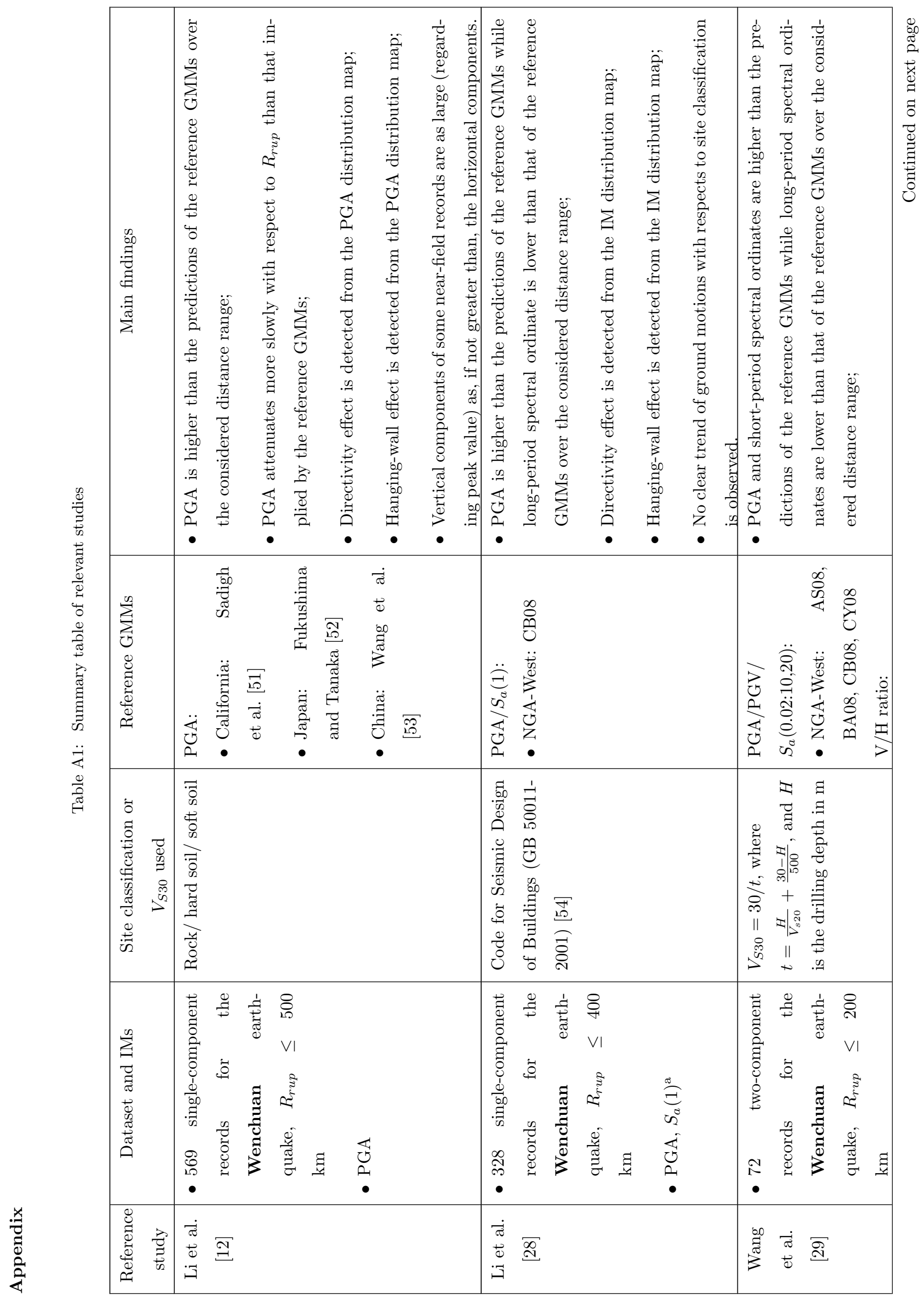




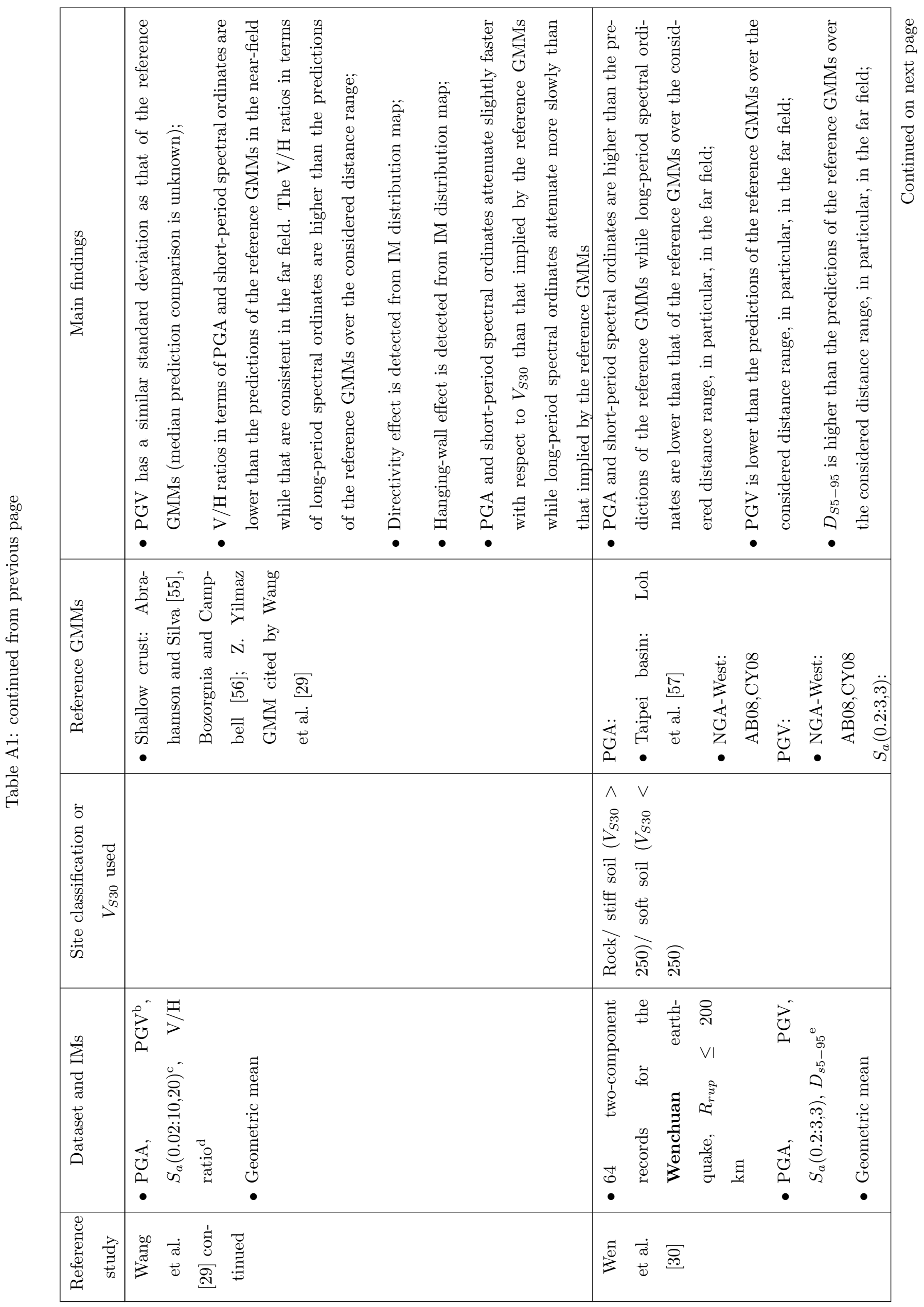




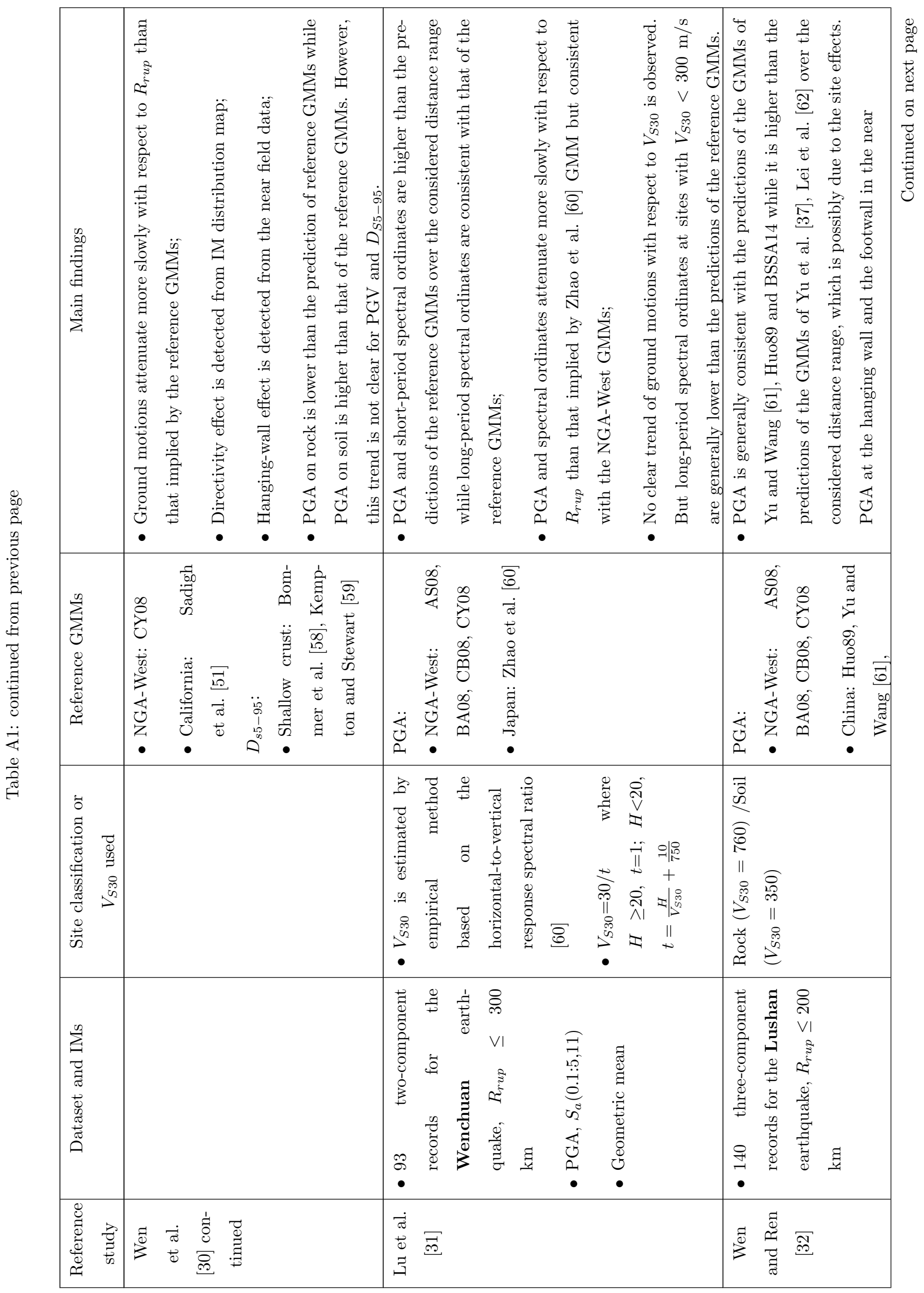




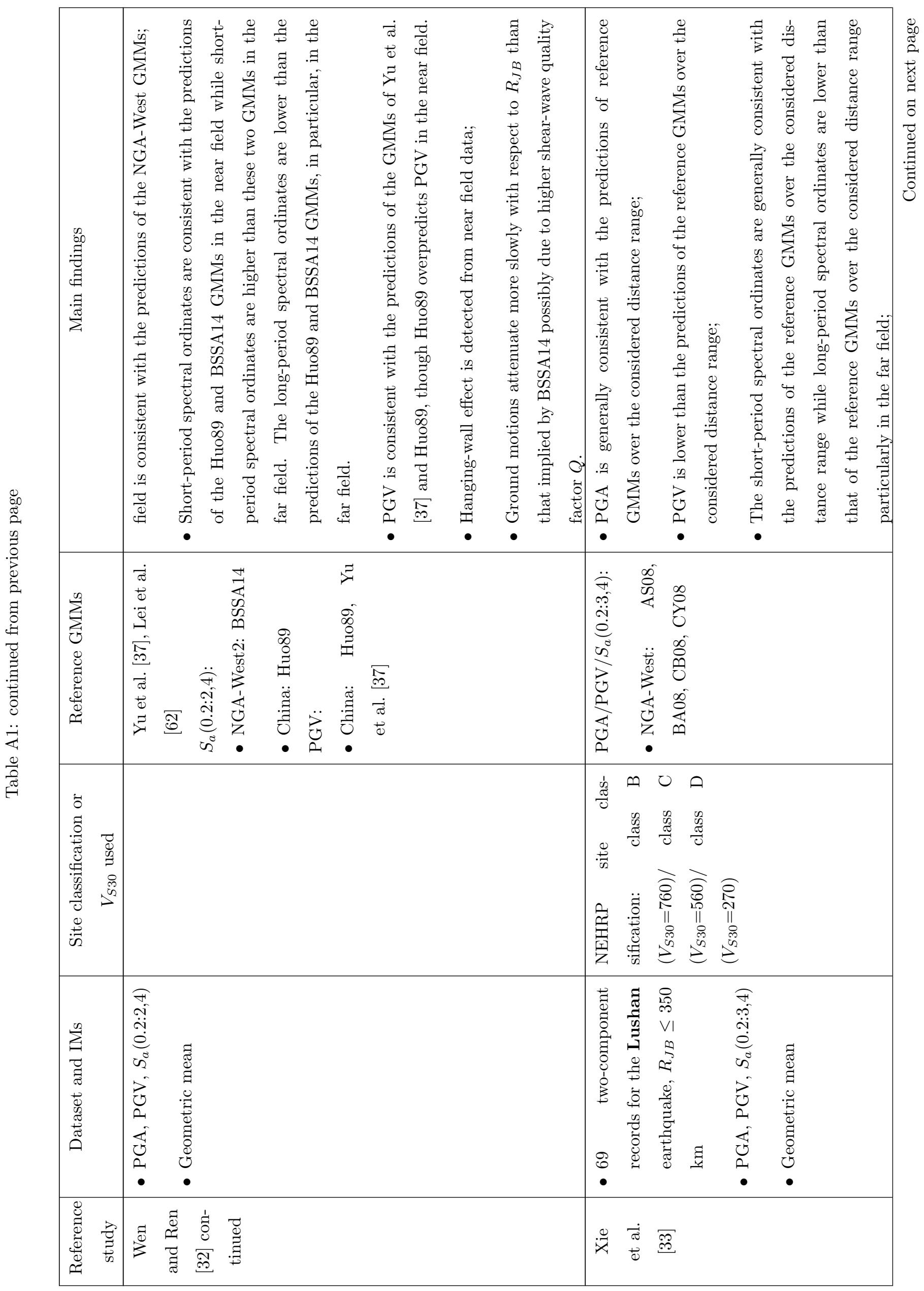




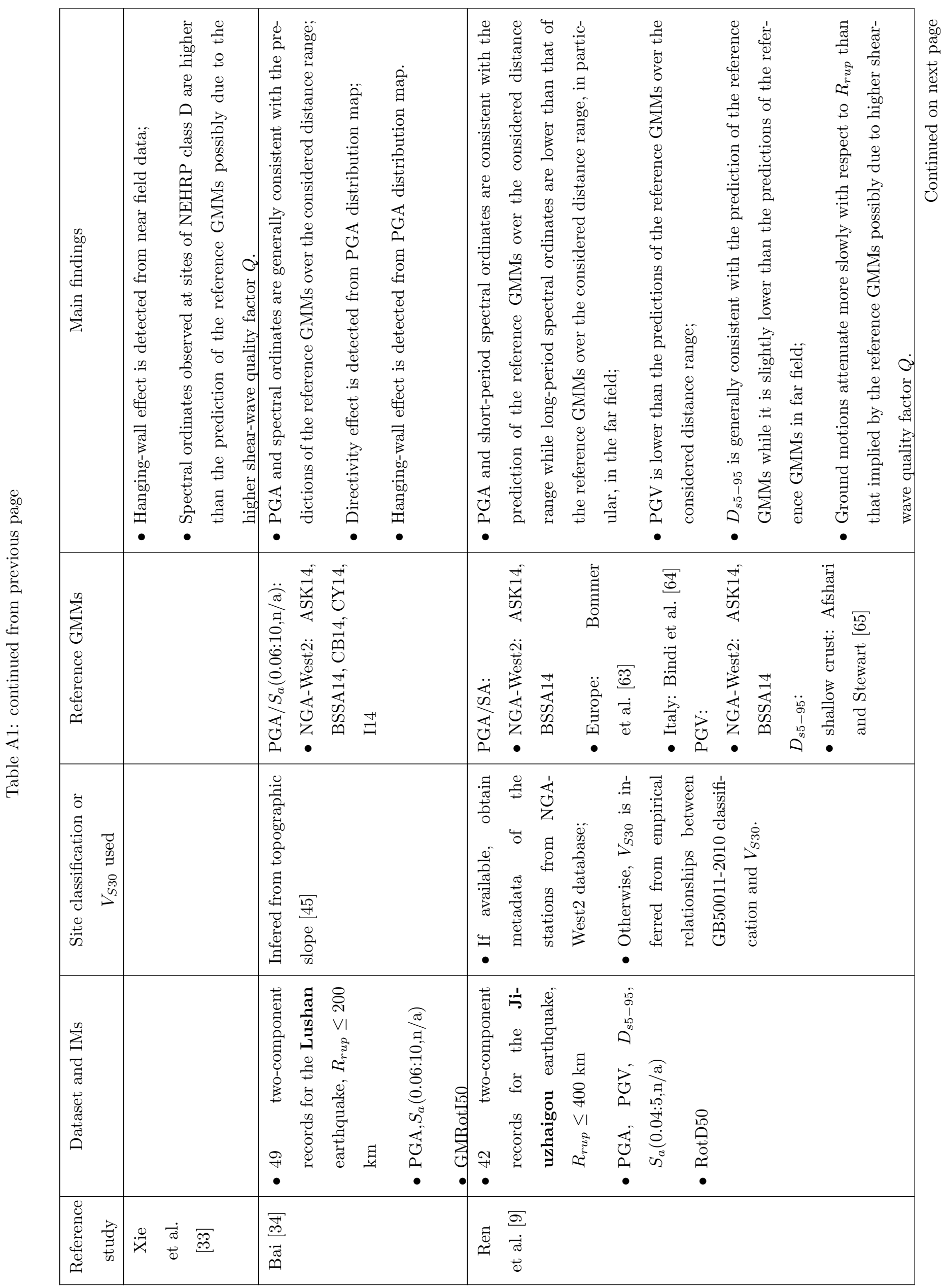




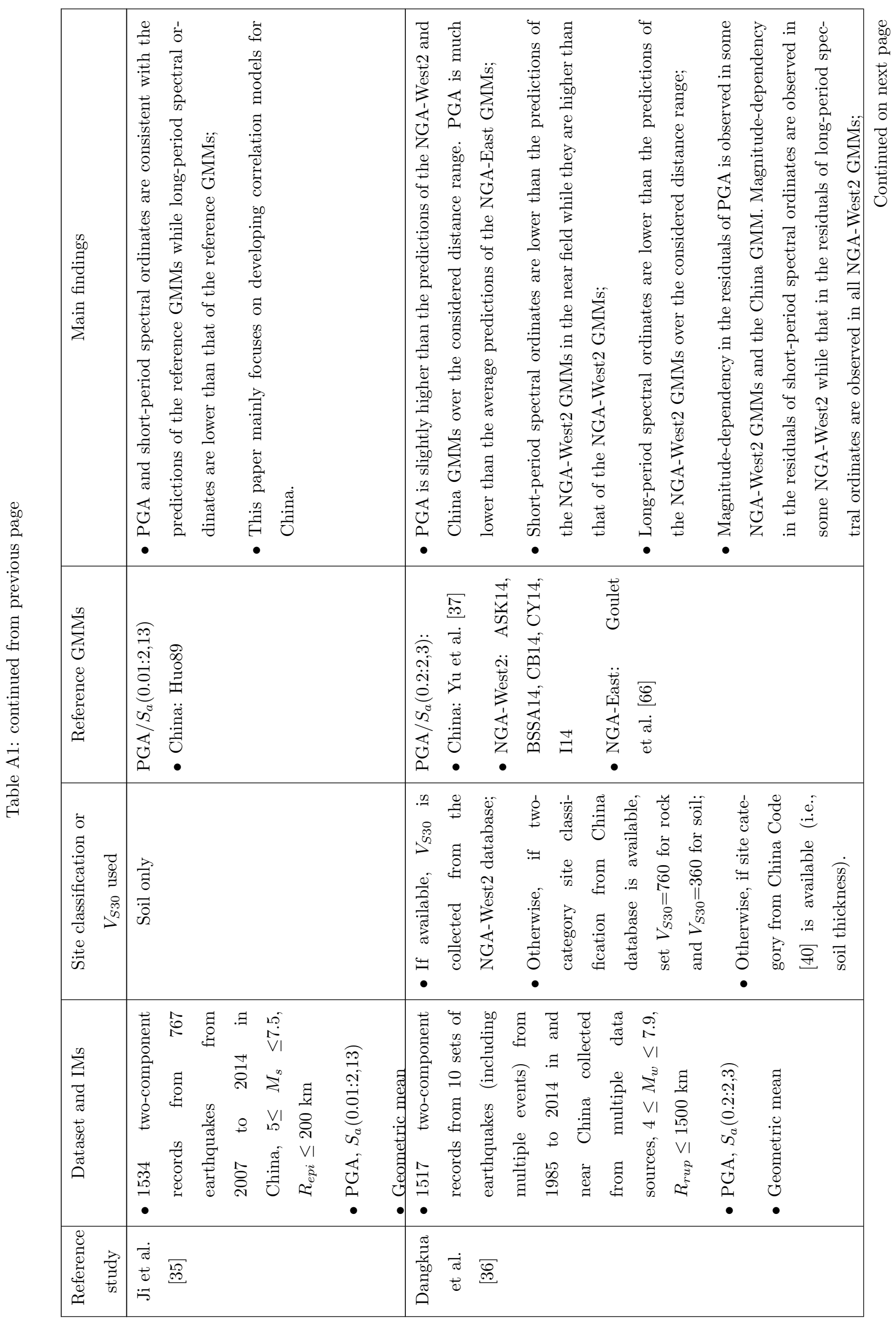




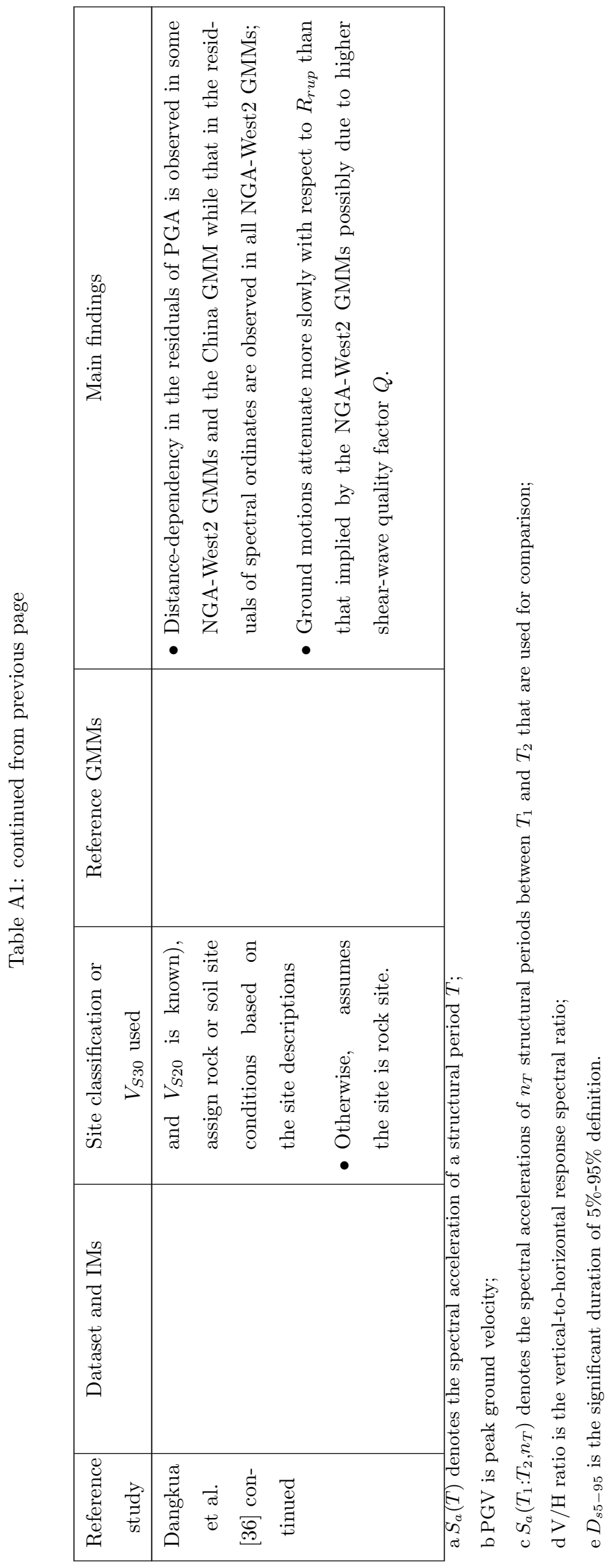

